\title{
Visible light promoted difunctionalization reactions of alkynes
}

\author{
Xiang Ren, Zhan Lu* \\ Department of Chemistry, Zhejiang University, Hangzhou 310058, Zhejiang, China
}

\section{A R T I C L E I N F}

\section{Article history:}

Received 18 November 2018

Accepted 8 December 2018

Published 5 July 2019

\section{Keywords:}

Visible light photocatalysis

Difunctionalization

Cyclization

Alkyne

Redox catalyst

\begin{abstract}
A B S T R A C T
Visible light promoted difunctionalization of alkynes is reviewed. The difunctionalization reaction is achieved by different reagents. Radicals such as carbon $\left(s p^{3}\right)$, carbon $\left(s p^{2}\right)$, and other heteroatom $(\mathrm{P}$, $\mathrm{S}, \mathrm{N}, \mathrm{Se}, \mathrm{O}$, and halide) radicals initiated by visible light can undergo radical addition to a carbon-carbon triple bond. Upon further transformation, the desired difunctionalized products are obtained. Some organometallic complexes can be activated by visible light; the difunctionalization of alkynes is catalyzed by these species. Other reagents like 1,3-dipole precursors could also react with alkynes to give difunctionalization products; here, the 1,3-dipole derivatives are obtained by visible light photocatalysis. So far, the strategy has been succeeded in the formation of $\mathrm{C}-\mathrm{C}$ bonds and $\mathrm{C}-\mathrm{X}$ bonds. Several valuable chemical skeletons have been constructed under mild conditions. However, high regio- and stereoselectivities in some direct difunctionalization methodologies are yet to be achieved.
\end{abstract}

(C) 2019, Dalian Institute of Chemical Physics, Chinese Academy of Sciences. Published by Elsevier B.V. All rights reserved.

\section{Introduction}

Alkynes are useful motifs that contain at least one carbon-carbon triple bond in which the carbon atoms are $s p$ hybridized. The carbon atoms are attached to each other by two $\pi$ bonds, in which the two $p$ orbitals in the carbon atoms overlap, and one $\sigma$ bond. The structure makes the molecule highly reactive and causes it to undergo various transformations [1-4]. Several novel organic transformations with alkynes have been explored to build valuable molecular skeletons in recent years [5-22]. Among these, difunctionalization of alkynes is an efficient and straightforward strategy for the synthesis of functionalized compounds, which can be transformed into diverse organic skeletons. As we approach an energy crisis, the development of sustainable organic transformations has become an urgent requirement. Solar energy, a renewable, accessible, and clean source of energy, has been applied in electric energy gen- eration [23-26], water decomposition [27-33], and carbon dioxide reduction [34]. Organic transformations utilizing visible light date back to the early 1910s [35]. However, the inability of most organic molecules to absorb visible light has limited visible light photochemical synthesis. By introducing visible light photocatalysts (PC), which absorb visible wavelengths of light and have a long lifetime for the photoexcited state, solar energy could be transformed into the chemical energy needed for organic transformations such as synthetic methodologies [36-44], syntheses of natural products [45-48], enantioselective catalysis [49], and polymerization [50,51]. In these processes, the ground state photocatalysts absorb visible light to afford photoexcited state photocatalysts, which could undergo a redox pathway or an energy transfer pathway [52,53]. In the reductive quenching pathway, the excited state photocatalysts (PC*) can be reduced by an electron donor (D) to afford the $\mathrm{PC}^{-}$ species, which is a strong reductant. The $\mathrm{PC}^{-}$species can un-

\footnotetext{
*Corresponding author. Tel: +86-571-88206919; E-mail: luzhan@zju.edu.cn

This work was supported by Zhejiang Provincial Natural Science Foundation of China (LR19B020001), the National Natural Science Foundation of China (21472162, 21772171), and the National Basic Research Program of China (2015CB856600).

DOI: S1872-2067(19)63278-X | http://www.sciencedirect.com/science/journal/18722067 | Chin. J. Catal., Vol. 40, No. 7, July 2019
} 

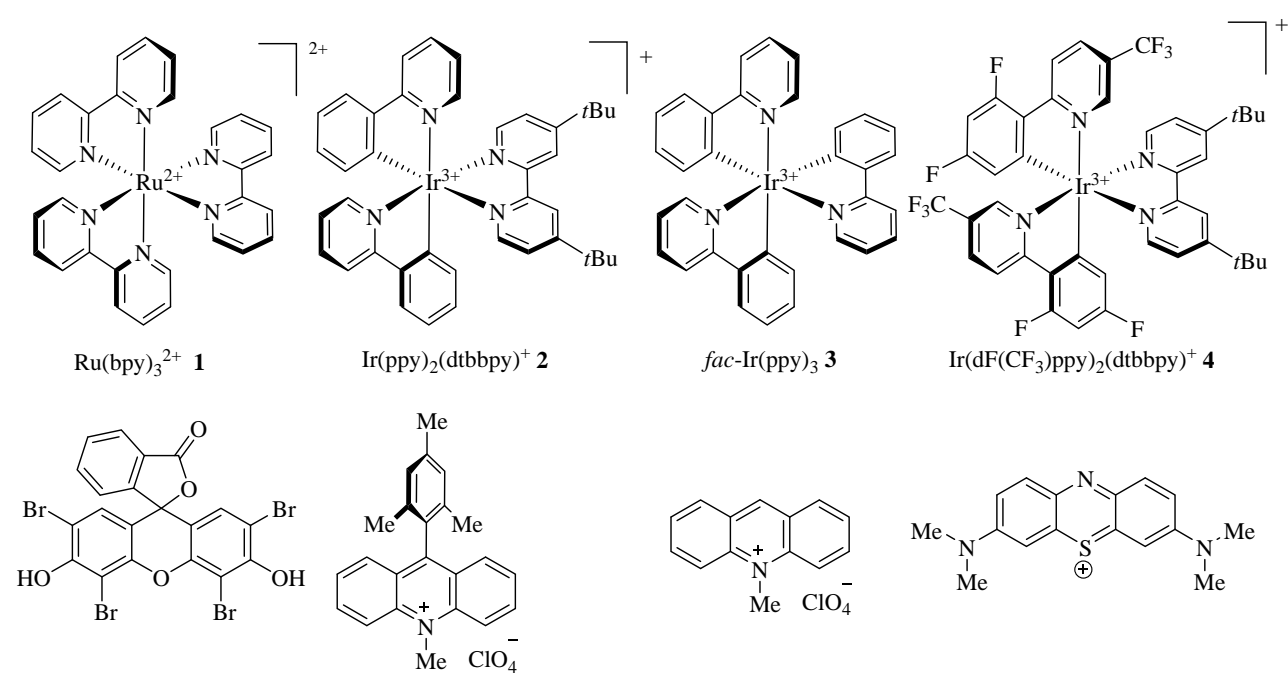

\begin{tabular}{|c|c|c|c|c|c|c|c|c|}
\hline \multirow[b]{2}{*}{ Catalyst } & \multirow{2}{*}{$\begin{array}{c}\text { Eosin Y } 5 \\
\mathbf{1}\end{array}$} & \multicolumn{2}{|c|}{ 10-methyl-9-mesitylacridinium 6} & \multicolumn{2}{|c|}{ 10-methyllacridinium 7} & \multicolumn{2}{|c|}{ Methylene Blue 8} & \multirow[b]{2}{*}{8} \\
\hline & & 2 & 3 & 4 & 5 & 6 & 7 & \\
\hline$\overline{E_{1 / 2}\left(\mathrm{PC}^{+} / \mathrm{PC}^{*}\right)(\mathrm{V})}$ & -0.81 & -0.96 & -1.73 & -0.89 & -1.11 & -0.49 & -0.46 & -0.30 \\
\hline$E_{1 / 2}\left(\mathrm{PC}^{+} / \mathrm{PC}\right)(\mathrm{V})$ & +1.26 & +1.21 & +0.77 & +1.69 & +0.78 & - & - & +1.13 \\
\hline$E_{1 / 2}\left(\mathrm{PC}^{*} / \mathrm{PC}^{-}\right)(\mathrm{V})$ & +0.77 & +0.66 & +0.31 & +1.21 & +0.83 & +2.18 & +2.32 & +1.60 \\
\hline$E_{1 / 2}\left(\mathrm{PC} / \mathrm{PC}^{-}\right)(\mathrm{V})$ & -1.33 & -1.51 & -2.19 & -1.37 & -1.06 & - & - & -0.68 \\
\hline
\end{tabular}

Scheme 1. Selected data for photocatalysts used for the difunctionalization of alkynes.

dergo single-electron oxidation with an electron acceptor $(\mathrm{S})$ or a metal salt $\left(\mathrm{M}^{n+}\right)$ to afford the radical anion $\left(\mathrm{S}^{\bullet}\right)$ or lower valency of the metal $\left(\mathrm{M}\left({ }^{n-1)+}\right)\right.$, accompanied by regeneration of the ground state photocatalysts. Alternatively, the $\mathrm{PC}^{*}$ can be oxidized by an electron acceptor (A) to afford the $\mathrm{PC}^{+}$species. In the most well-studied system, the $\mathrm{PC}^{+}$has a strong oxidative potential, which enables the capture of an electron from an electron donor $(\mathrm{S})$ or a metal salt $\left(\mathrm{M}^{n_{+}}\right)$to afford the radical cation $\left(\mathrm{S}^{\bullet+}\right)$ or high valency of metal salt $\left(\mathrm{M}^{n+1}\right)$. Simultaneously, ground state photocatalysts are obtained. However, an energy transfer pathway can also occur when the triplet state energy of the substrates $(\mathrm{S})$ or metal complexes $\left(\mathrm{M}^{n+*}\right)[54,55]$ matches the triplet state energy of the photocatalysts. After energy transfer from the excited state photocatalysts ( $\left.\mathrm{PC}^{*}\right)$, the triplet state of substrates $\left(\mathrm{S}^{*}\right)$ or metal complexes $\left(\mathrm{M}^{n+*}\right)$ can be ob- tained and the ground state photocatalysts were afforded to complete the catalytic cycle.

It should be noted that the photoinduced reactions could also proceed smoothly without photocatalysts. Some substrates absorbed visible light to undergo a homolytic bond cleavage to afford radicals [56-59]. The electron-donor-acceptor (EDA) complexes could undergo a charge transfer process under visible light irradiation to afford the radical. The strategies mentioned above were utilized in difunctionalization reactions [60-64]. In addition, a similar process also occurred with some organometallic reagents [65]. Complexes which were generated from organometallic reagents and substrates absorbed visible light to yield the activated organometallic species, which could be used for the further transformations.

This review focuses on the visible light promoted difunc-

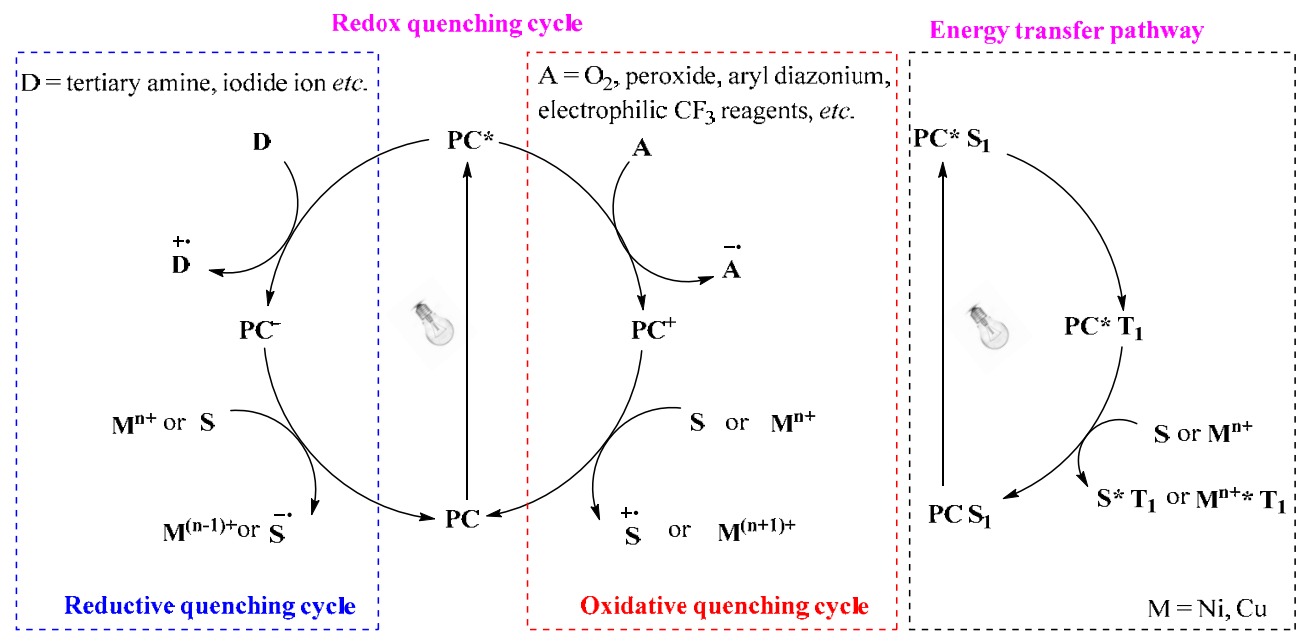

Scheme 2. Catalytic modes of the photocatalyst. 
homolytic cleavage

$$
\mathrm{X}^{-\mathrm{Y}} \stackrel{\text { visible light }}{\longrightarrow} \mathrm{X}^{\cdot} \mathrm{Y}^{*}
$$

EDA complex formation

$$
\begin{aligned}
\mathrm{X}+\mathrm{Y} \longrightarrow \mathrm{X}^{--\mathrm{Y}} \stackrel{\text { visible light }}{\text { visible light }} \mathrm{X}^{+\cdot} \overrightarrow{\mathrm{Y}}^{\mathrm{n}} \\
\mathrm{M}^{\mathrm{n}} \mathrm{X}+\mathrm{Y} \longrightarrow \mathrm{XM}_{\mathrm{Y}}^{\mathrm{n}+1} \mathrm{X} \quad \overrightarrow{\mathrm{Y}}
\end{aligned}
$$

Scheme 3. Visible light promoted reactions without the photocatalyst.

tionalization reactions of alkynes. The hydroelementation reactions of alkynes are not included. The reactions are categorized based on the different reagents: $\mathrm{Cs} p^{3}$ radical reagents, $\mathrm{C} s p^{2}$ radical reagents, heteroatom radical reagents, organometallic reagents, and other reagents.

\section{2. $C s p^{3}$ radical reagents}

The $C s p^{2}-C s p^{3}$ bond formation via radical addition to alkynes with $\mathrm{Csp} p^{3}$ radical is an important route. The generation of a $C s p^{3}$ radical is the key step to initiate difunctionalization reactions. $\mathrm{Cs} p^{3}$ radicals were obtained from different reagents: fluoro-containing reagents, alkyl halides, and other $\mathrm{Cs} p^{3}$ radical reagents.

\subsection{Fluoro-containing reagents}

The unique properties of fluorine have greatly enriched methodologies to synthesize fluoro-containing compounds. In our previous review on difunctionalization of alkenes [66], fluoro-containing reagents, such as perfluoroalkyl iodides, were reduced via visible light photocatalysts to give perfluoroalkyl radicals. A radical addition to alkenes occurs, forming a carbon centered radical species. A similar process could proceed smoothly when using alkynes as substrates. Perfluoroalkyl halides, bromodifluoroacetates, and $\mathrm{CF}_{3}$ reagents can be used for the formation of fluoro-containing derivatives under visible light irradiation.

\subsubsection{Perfluoroalkyl halides}

Visible light promoted atom-transfer-radical-addition (ATRA) reaction of alkynes could be achieved by perfluoroalkyl iodides. In 2012, Stephenson and co-workers explored visible light promoted ATRA reaction of terminal alkynes with perfluoroalkyl iodides [67] (Scheme 4). The reaction was conducted using $\mathrm{Ru}(\mathrm{bpy}){ }_{3} \mathrm{Cl}_{2}$ as a photocatalyst and Na-ascorbate as a reductant under visible light irradiation. The terminal al-

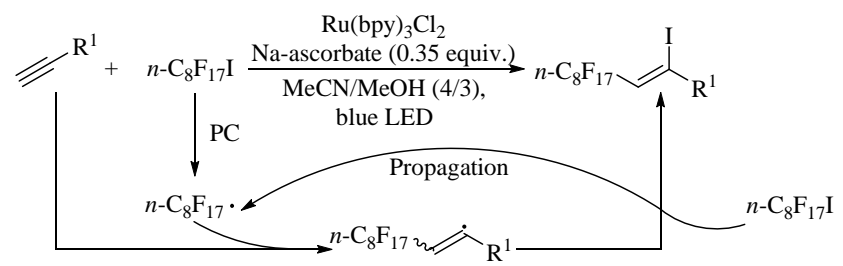

Scheme 4. ATRA reaction of alkynes with perfluoroalkyl iodides via visible light photocatalysis. kynes reacted with $n$ - $\mathrm{C}_{8} \mathrm{~F}_{17} \mathrm{I}$ to give perfluoroalkyl substituted vinyl iodides in $94 \%-96 \%$ yields, with $1.8 / 1$ to $2 / 1 E / Z$ ratios. A propagation pathway was proposed rather than the SET process in this transformation. Similar methodologies were achieved by Cho and co-workers in 2014 [68] and 2016 [69] (Scheme 5). The corresponding fluoro-containing vinyl iodides were obtained. In 2017, Shibata and co-workers explored a visible light induced ATRA reaction of alkynes with perfluoroalkyl iodides using a zinc complex as the photocatalyst [70]. Yajima and co-workers explored an ATRA reaction of alkynes using eosin Y as the photocatalyst [71]. In 2018, Yu and Reiser also achieved photomediated ATRA reactions. In Yu's method, perfluoroalkyl radicals were generated by photodecomposition of the $\mathrm{N}$-fluoroalkyl bond, which were generated from the combination of perfluoroalkyl iodides and secondary amine [72]. In Reiser's work, photoinduced ATRA reaction of arylacetylenes catalyzed by $\mathrm{Cu}(\mathrm{dap})_{2} \mathrm{Cl}$ proceeded better than the reaction catalyzed by $\mathrm{Ir} / \mathrm{Ru}$ photocatalyst [73].

\subsubsection{Bromodifluoroacetates}

Visible light induced aryldifluoroacetylation of alkynes was achieved by Fu and co-workers in 2015 [74] (Scheme 6). Synthesis of 3-difluoro acetylated coumarins from phenyl alkynoates and 2-bromo-2,2-difluoroacetate could be realized by employing fac-Ir(ppy) 3 as a catalyst and potassium carbonate as a base under irradiation by blue LEDs. Similar strategies were used for the syntheses of 3-aryl-2-difluoroacetyl indenones [75,76] and 3-difluoro acetylated quinolines [77]. In addition, Kuang and $\mathrm{Wu}$ achieved a vinyl difluoroalkylation and aminosulfonylation of alkynes with 2-bromo-2,2-difluoroacetate [78]. This reaction with four components proceeded through a tandem radical process, with the insertion of sulfur dioxide to afford the desired difluoroalkylation and aminosulfonylation products in 45\%-95\% yields with high stereoselectivity.

\subsection{3. $\mathrm{CF}_{3}$ radical reagents}

According to Koike and Akita in 2015 [79], using $\operatorname{Ir}(\text { ppy })_{2}$ (dtbbpy) $\left(\mathrm{PF}_{6}\right)$ as a photocatalyst and 2,6-ditertbutylpyridine as a base, internal aryl alkynes and Umemoto reagent were converted into tetra-substituted trifluoromethylated alkenes in $30 \%-86 \%$ yields, and $61 / 39$ to $97 / 3 E / Z$ ratios. Similar strategies were conducted by Wu [80] and Han $[81,82]$ to achieve intramolecular trifluoromethylation cyclization and oxidative trifluoromethylation reactions, respectively (Scheme 7).

Trifluoromethanesulfonyl chloride and its derivatives can be used as a source of trifluoromethyl radicals. By the SET pro-

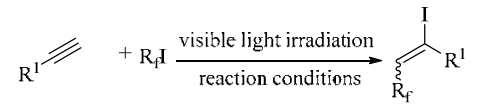

$$
\begin{aligned}
& 2014 \text { Cho: Ru(phen })_{3}^{2+} \quad 13 \text { examples. } 78-95 \% \text { yields, } E: Z 2.6: 1 \text { to } E(Z) \text { only } \\
& 2016 \text { Cho: Ru(phen })_{3}^{2+} \quad 10 \text { examples. } 52-95 \% \text { yields, } E: Z \text { I:1.1 to } 1: 3.8 \\
& \text { 20.7 Shibata: } Z n \text { complex(TFEOZnPc) } 1 \text { example. } 83 \% \text { yields } \\
& \text { 20.7 Yajima: esoin } Y \quad 7 \text { examples. } 73-89 \% \text { yields, } E: Z 54: 46 \text { to } 87: 13 \\
& 2018 \mathrm{Yu}: \mathrm{Bn}_{2} \mathrm{NH} \quad 23 \text { examples. } 50-95 \% \text { yields, } L: Z 2.2: 1 \text { to }>20: 1 \\
& 2018 \text { Reiser: } \mathrm{Cu}\left(\text { dap }_{2}{ }^{+} \quad 12 \text { examples. } 40-93 \% \text { yields, } E: Z 50: 50 \text { to }>99: 1\right.
\end{aligned}
$$

Scheme 5. Perfluoroalkylation reactions of alkynes promoted by visible light. 


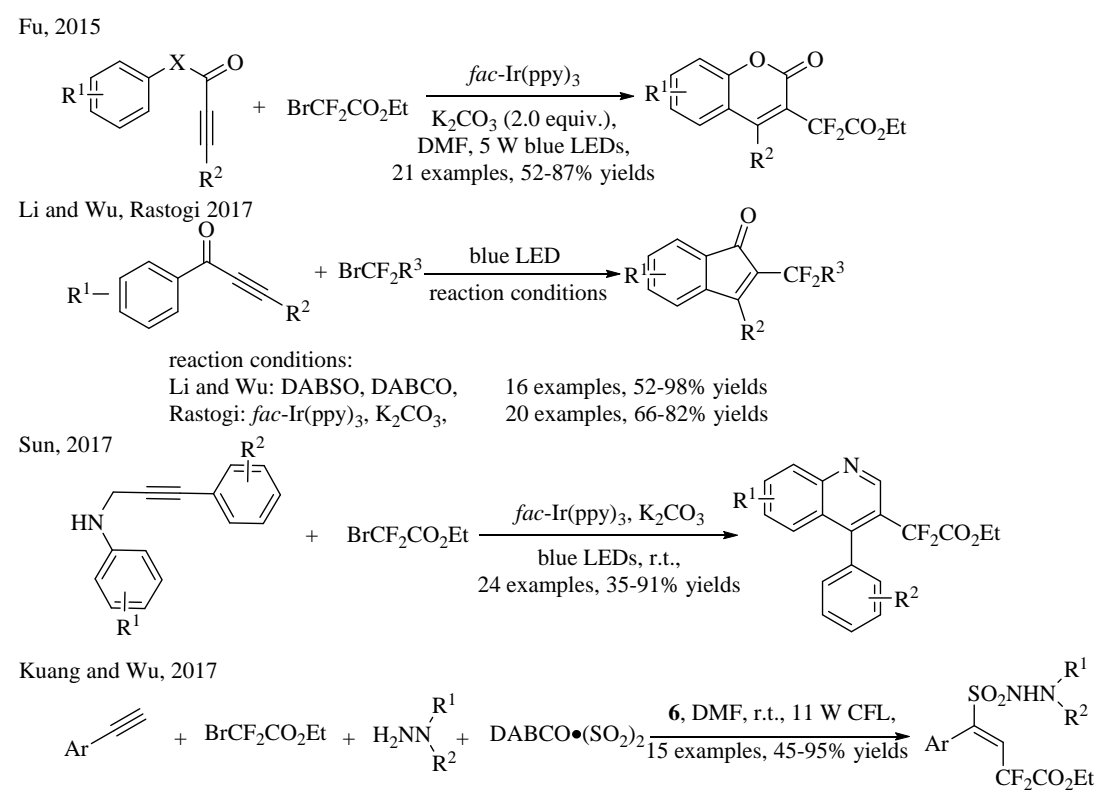

Scheme 6. Visible light induced difunctionalization reactions with bromodifluoroacetate reagents.

cess, $\mathrm{CF}_{3}$ radical can be generated along with the release of sulfur dioxide. In 2017, Song and co-workers explored a photomediated chlorotrifluoromethylation of alkynes using trifluoromethanesulfonyl chloride as a $\mathrm{CF}_{3}$ radical source [83]. This reagent was also used for the synthesis of 3-trifluoromethyl coumarins [84-86] (Scheme 8).

\subsection{Alkyl halides}

Alkyl halides were widely used as $\mathrm{Cs} p^{3}$ radical sources in radical reactions. This is because alkyl halides are easily available and can undergo a C-X bond dissociation to afford $\mathrm{Csp}^{3}$ radicals. In visible light promoted reactions utilizing alkyl halides as radical precursors, the $\mathrm{C}-\mathrm{X}$ bond dissociation takes place to afford the desired $\mathrm{C} s p^{3}$ radicals.
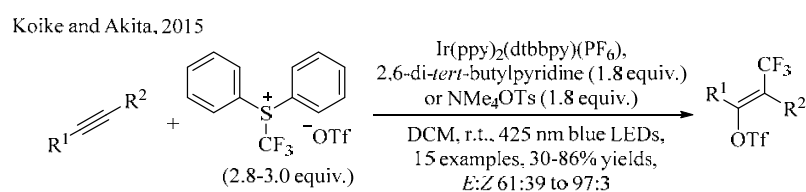

Kuang and $\mathrm{wu}, 2016$
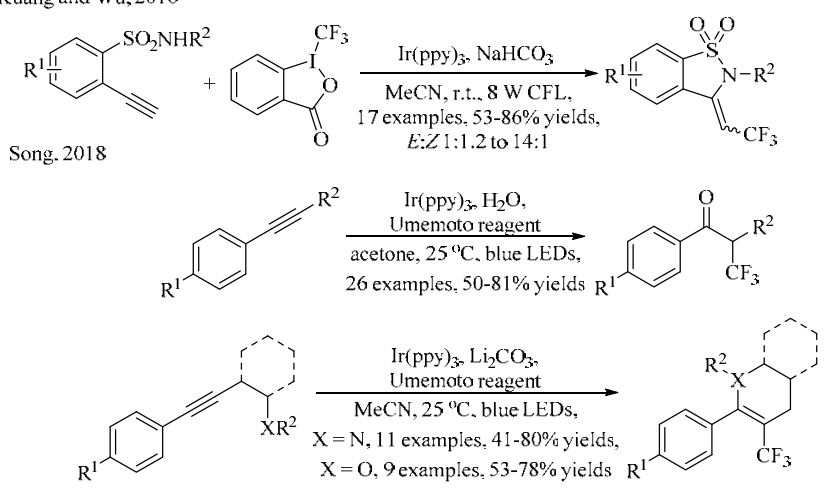

Scheme 7. Visible light promoted trifluoromethyloxylation of alkynes via trifluoromethylated reagents.
A visible light promoted radical cyclization-divinylcyclopropane rearrangement reaction was disclosed by Stephenson and co-workers in 2011 [87]. Using $\operatorname{Ir}(\text { ppy })_{2}(\mathrm{dtbbpy})\left(\mathrm{PF}_{6}\right)$ as a photocatalyst and $\mathrm{Et}_{3} \mathrm{~N}$ as a base under visible light irradiation, diaryl-substituted bromo cyclopropanes could be transformed into the desired tricyclic pyrrolidinones in 32\%-91\% yields (Scheme 9). In this transformation, the cyclopropane radical was generated by reduction of the IrII catalyst, and the 5-exo-dig radical cyclization could occur, followed by hydrogen-atom abstraction of vinyl radicals. The vinylcyclopropane (VCP) intermediate underwent a $[3,3]$ sigmatropic rearrangement to afford the desired products. However, single electron reduction of the VCP could also take place in this transformation (Scheme 10).

The Melchiorre group explored the photo-organocatalysis of ATRA reaction of alkynes in 2014 [88]. The bromo-2-malonate reacted with but-3-yn-1-ol leading to the corresponding bromocarbonation product in $60 \%$ yield (complete $E$ isomer) (Scheme 11). In addition, an energy transfer pathway was

Han, 2017

$$
\underset{\substack{\mathrm{MeCN}, \mathrm{K}_{2} \mathrm{CO}_{3} \text {, r.t., blue LEDs, } \\ 20 \text { examples, 34-85\% yields }}}{\mathrm{R}^{1}} \underset{\mathrm{Ar}}{\text { fac- } \mathrm{Cr}(\mathrm{ppy})_{3}, \mathrm{CF}_{3} \mathrm{SO}_{2} \mathrm{Cl}}
$$

Fu, Cai, Xiong

$$
\begin{aligned}
& 2017 \mathrm{Fu}, 24 \text { examples, 52-80\% yields, } \\
& 2018 \mathrm{Cai}, 14 \text { examples, 28-84\% yields, } \\
& 2018 \text { Xiong, } 27 \text { examples, 52-85\% yields }
\end{aligned}
$$

Scheme 8. Visible light promoted difunctionalization of alkynes with trifluoromethanesulfonyl derivatives. 


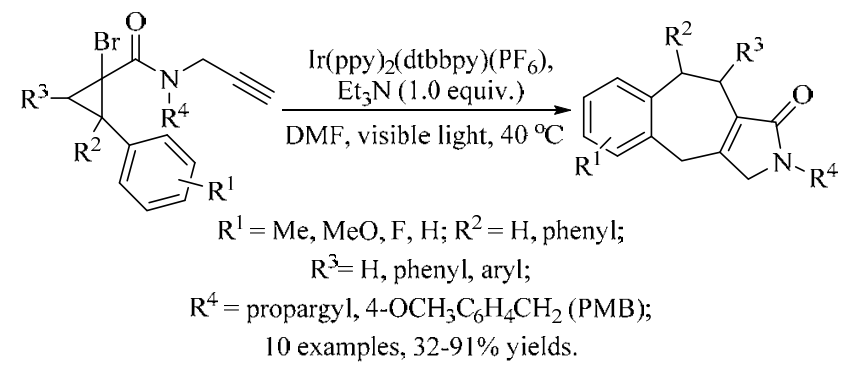

Scheme 9. Visible light induced synthesis of tricyclic pyrrolidinones with VCP.

proposed in this transformation; the $\mathrm{C}-\mathrm{Br}$ bond cleavage from bromo-2-malonate could occur after the energy transfer process of photoexcited $p$-anisaldehyde.

In 2013, Yu and Zhang explored the visible light induced synthesis of naphthols and furans [89]. Using $\operatorname{Ir}(\text { ppy })_{2}($ dtbbpy $)\left(\mathrm{PF}_{6}\right)$ as a photocatalyst and disodium hydrogen phosphate as a base, aryl ketobromides and alkynes were transformed into poly-substituted naphthols in 43\%-98\% yields with high regioselectivity (Scheme 12). When using ethanol as the solvent and 2-bromocyclohexane-1,3-dione derivatives as the activated bromides, the desired furan derivatives were obtained in 33\%-98\% yields. Carbazole derivatives were also obtained by a similar method using indole-derived bromide compounds as substrates, which was explored by Xiao and Lu in 2016 [90].

In addition, the $\mathrm{Cs} p^{3}$ radicals generated from activated halides via visible light photocatalysis were further utilized in cyclization of alkynes (Scheme 13). In 2017, Zhu and co-workers synthesized cyclohexylidenehydrazine-fused polycyclics from 2-ethynylaldehyde hydrazones and $\alpha$-bromo carbonyls under visible light irradiation [91]. The next year, visible light promoted synthesis of 3-cyanomethylated coumarins was reported by Li's group [92]. Very recently, the synthesis of spiro[4,5] deca-1,6,9 trieno-8-ones was also reported by Zhang and co-workers, with 2-bromo-1,3-dicarbonyl derivatives as the activated halide [93]. It should be noted that

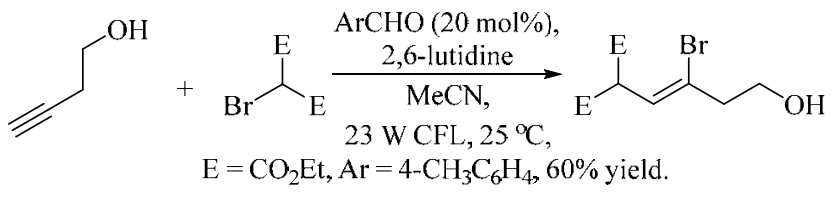

Scheme 11. ATRA bromocarbonation reaction of alkynes via $p$-anisaldehyde as a catalyst.

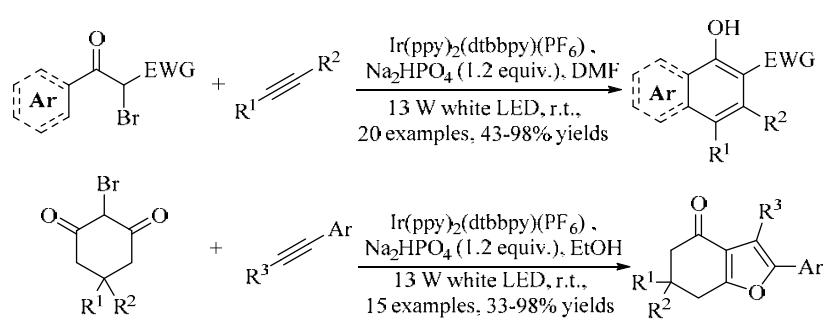

Scheme 12. Visible light induced synthesis of poly-substituted naphthols and furans from alkynes.

2-bromo-malononitriles could also be utilized in visible light promoted difunctionalization of alkynes, which was explored by Wang and Meng in 2016 [94].

The reactions mentioned above that use activated organic halides contain a C-X bond adjacent to the $\pi$-system or electron withdrawing groups that could undergo a rapid SET process. However, the high reductive potential of unactivated alkyl halides $\left(E_{\text {red }}[n-\mathrm{BuI}]=-2.5 \mathrm{~V}\right.$ vs. SCE in MeCN) [95] was the major challenge to obtain these $\mathrm{Csp}^{3}$ radicals. In 2013, Li and Yao explored the intermolecular visible light promoted atom transfer radical cyclization (ATRC) reactions of 2-(iodomethyl) cyclopropane-1,1-dicarboxylate with alkynes [96] (Scheme 14). In 2017, Martin and Juliá-Hernández achieved a visible light induced intramolecular ATRC reaction using alkyl halides [97]. In these two reactions, unactivated alkyl iodides were used as substrates. Tertiary amines were also required in these strategies.

Very recently, Nagib and co-workers reported a visible light induced ketyl-alkyne coupling reaction [98]. The aliphatic ketyl radical was hard to obtain because of the high reductive poten-

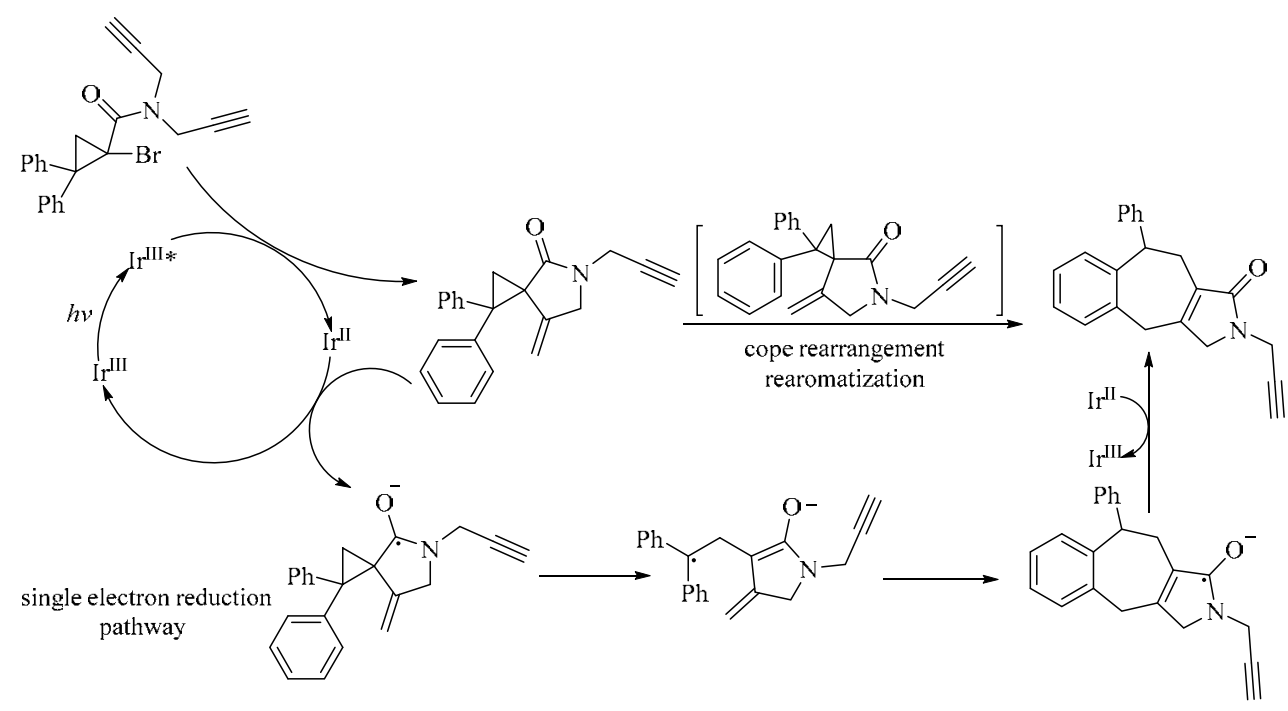

Scheme 10. The proposed cyclization-divinylcyclopropane rearrangement reaction. 
Zhu, 2017<smiles>[R]CC#CC(=O)Oc1ccc([R])cc1</smiles>

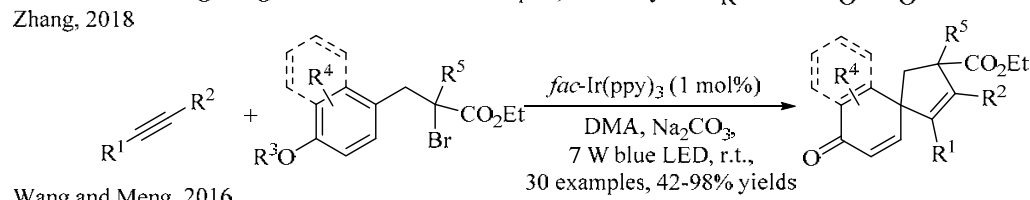

Wang and Meng, 2016

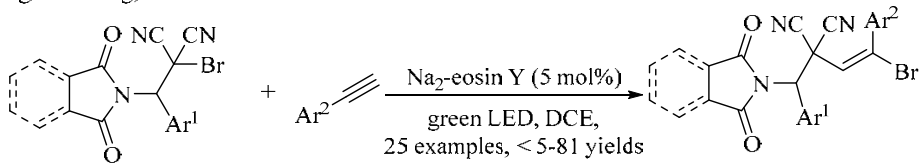

Scheme 13. Visible light induced difunctionalization of alkynes with activated alkyl bromides.

tial of the corresponding aldehydes ( $>-2.2 \mathrm{~V}$ ) [99]. The reaction of acetyl iodide with aliphatic aldehydes gave $\alpha$-acetoxyiodides, which could undergo C-I bond dissociation by activated manganese catalyst under visible light irradiation to afford the ketyl radical species. Using this method, the corresponding vinyl iodides were obtained in 36\%-81\% yields, with 2:1 to $>20: 1 Z / E$ ratios (Scheme 15). The reaction underwent a chain propagation process. Visible light irradiation could promote the efficiency and selectivity of the transformation.

$$
\text { Martin and Juliá-Hernández, } 2017
$$

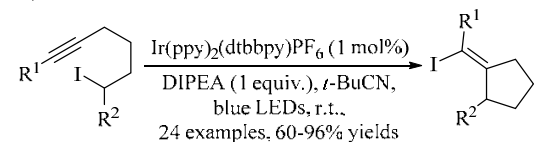

Scheme 14. Visible light induced difunctionalization of alkynes with unactivated alkyl iodides.

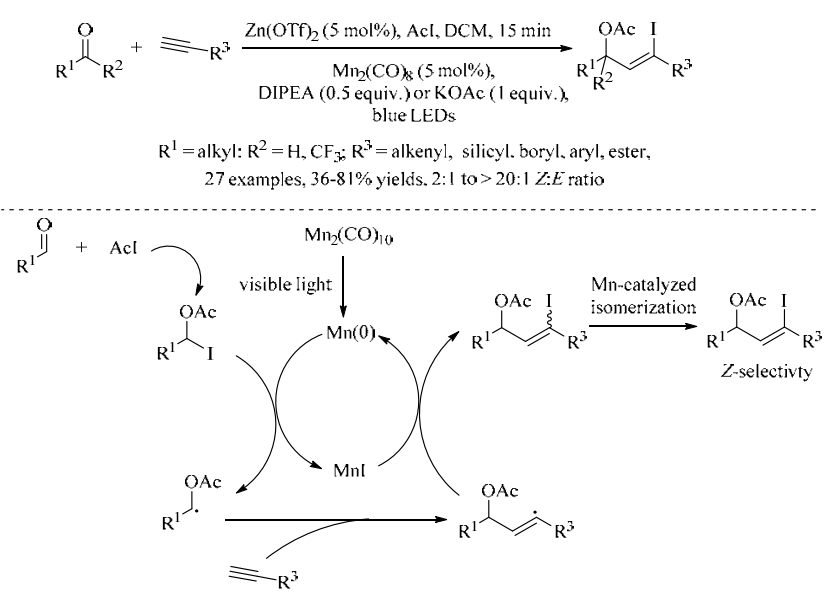

Scheme 15. Visible light induced ketyl-alkyne coupling reactions.

\subsection{Other $C s p^{3}$ radical reagents}

Several methodologies for carbon radical generation by direct carbon-hydrogen bond cleavage were achieved via the hydrogen abstraction of nitrogen or oxygen radical generated by photocatalysis [100-108].

In 2016, Xie and co-workers reported a synthetic strategy for coumarins initiated by visible light, using hydroperoxide as an oxidant [109] (Scheme 16). The tert-butoxyl radical could abstract a hydrogen atom from an ether to afford $\alpha$-oxo radical which reacts with alkynes. With this strategy, coumarin products were obtained in $42 \%-82 \%$ yields. A similar strategy was applied by Lei and co-workers [110], using $\left(\mathrm{NH}_{4}\right)_{2} \mathrm{~S}_{2} \mathrm{O}_{8}$ as a hydrogen abstractor and methylene blue as a catalyst. Meanwhile, Zhou and co-workers reported a visible light mediated Xie, 2016<smiles>[Y]C#CC(=O)Oc1cc[Y10](C)cc1</smiles>

Lei, 2017<smiles>[Y4]Cn1c([Y])c(C([R])=O)c2ccccc21</smiles>

Scheme 16. Carbocyclization of alkynes via visible light photocatalysis. 
Xia. 2016<smiles>[Y]C=C([Y7])/C(=C\[Y7])C(=O)N([Y])c1cc[Y10]cc1C#N</smiles><smiles></smiles>

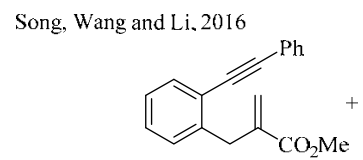

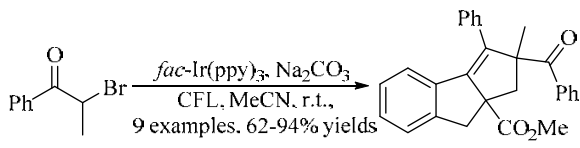

Kumar 2017<smiles>[R]C#Cc1ccccc1OC=C</smiles>

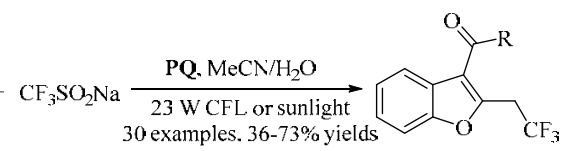<smiles>O=C1C(=O)c2ccccc2-c2ccccc21</smiles>

Li and Song, 2018<smiles>[Y]C#Cc1cc[Y1]cc1N([Y])C(=O)C([Y4])=C</smiles>

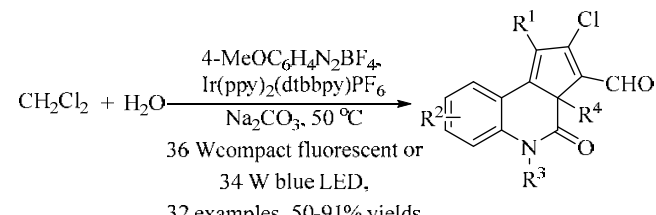

32 examples. $50-91 \%$ yields

Scheme 17. Visible light induced tandem cyclization of alkynes.

method for the synthesis of 3-acylindoles through the intramolecular cyclization of $N, N$-dialkylamines [111]. Similarly, Xia and co-workers introduced an enamine moiety into the substrates, which could be oxidized by a photocatalyst after the tautomerization to afford the $C s p^{3}$ radical, followed by further transformation to afford quinolones [112].

In 2016, Xia and co-workers reported a visible light induced 1,7-enyne cascade bicyclization reaction [113] (Scheme 17). Similarly, visible light induced cascade cyclization reactions were reported by Li and Wang [114], Kumar [115], and Li [116]. Other radical precursors such as the thiyl radical could also be used in similar tandem cyclization reactions $[117,118]$.

\section{3. $C s p^{2}$ radical reagents}

\subsection{Aryl radical reagents}

In 2012, König and co-workers achieved a visible light promoted synthesis of benzothiophene derivatives. Using eosin Y as a photocatalyst, aryl radicals could be generated from $o$-methylthio-arenediazonium salts under visible light irradiation. These radicals reacted with alkynes to afford the corresponding benzothiophene derivatives in 30\%-81\% yields [119] (Scheme 18). Similarly, Zhou and co-workers explored a [4+2] benzannulation of aryldiazonium salt with alkynes [120]. A similar reaction was reported by Cho and co-worker in 2017 [121], which contained a diazotization process with biarylamines and tert-butyl nitrite as well as a [4+2] benzannulation reaction.

Similarly, Wang and Ni described a visible light driven domino process of alkynes with aryl diazonium salts [122]. The desired $\alpha$-chloro aryl ketones were obtained in $22 \%-71 \%$ yields and $\alpha$-alkoxy aryl ketones were obtained in 36\%-58\% yields. In 2017, the same reaction was carried out by Wang and co-workers using a $\mathrm{TiO}_{2}$ complex as a photocatalyst [123]

\section{(Scheme 19).}

Benzotriazole derivatives could be transformed into the desired aryl radicals by a photoinduced denitrogenation process, which was similar to the generation of aryl radicals from aryl diazonium salts. Yu and co-workers explored the visible light induced synthesis of isoquinolines in 2015 [124]. Glorius and co-workers also reported a photoinduced synthesis of 2-substituted indoles [125] (Scheme 20).

Aryl radicals could also be generated from aryl halides under visible light irradiation. In 2016, Yuan and co-workers achieved the photoinduced synthesis of 2-substituted benzothiophenes [126] (Scheme 21). The intermediate, which was generated from $\mathrm{KOH} / \mathrm{DMSO}$ superbase and 2-halogenthioanisoles, could undergo a single electron transfer under visible light irradiation to afford the aryl radicals. These radicals could react with alkynes, which could undergo a process similar to that reported by König.

Li and co-workers explored a new methodology for the construction of functionalized $1 \mathrm{H}$-indenes via visible light photo-

$$
\begin{aligned}
& \text { König, } 2012 \\
& \text { I }
\end{aligned}
$$

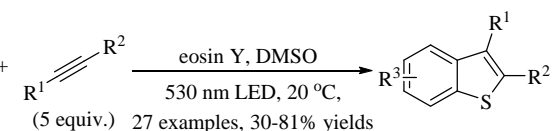
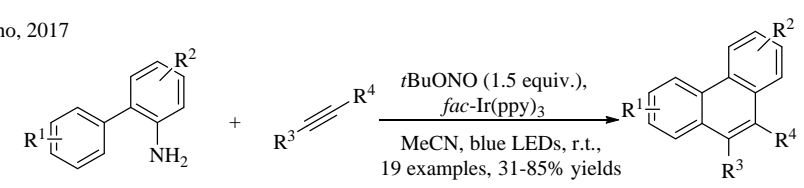

Scheme 18. Visible light promoted difunctionalization reaction with aryldiazonium salts. 
Wang and $\mathrm{Ni} .2016$

Wang, 2017<smiles></smiles>

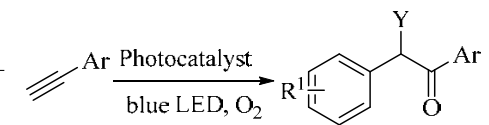

Conditions $\mathrm{A}$ : $\operatorname{eosin} \mathrm{Y}, \mathrm{NaCl}, \mathrm{MeOH}$ or $\mathrm{ROH} / \mathrm{MeCN}$, $\mathrm{Y}=\mathrm{Cl}$, 15 examples, $22-71 \%$ yields, $\mathrm{Y}=\mathrm{OR}$, 9 examples, $36-58 \%$ yields, Conditions $\mathrm{B}$ : $\mathrm{TiO}_{2}$ complex, $\mathrm{NaCl}, \mathrm{MeOH}$ $\mathrm{Y}=\mathrm{Cl}, 23$ examples, $56-78 \%$ yields

Scheme 19. Visible light mediated synthesis of $\alpha$-chloro aryl ketones and $\alpha$-alkoxy aryl ketones.

catalysis in 2012 [127]. Using aryl sulfonyl chlorides as the source of aryl radicals, the arylative cyclization products were obtained in 6\%-94\% yields. In this transformation, aryl sulfonyl chlorides could undergo an oxidation process promoted by visible light. With the removal of sulfur dioxide, the expected aryl radicals could be obtained. When $o$-azidoaryl alkynes were used as the substrates instead of $o$-alkyl aryl alkynes, the desired 2,3-diaryl indoles were obtained [128]. Similarly, a tandem cyclization of 1,6-enynes was achieved by using aryl sulfonyl chlorides as the aryl radical sources [129] (Scheme 22).

\section{2. $C s p^{2}$ radicals generated from cascade radical reaction}

In 2014, Yu and co-workers explored a visible light promoted synthesis of quinolone derivatives from phenyl isocyanides and bromo-substituted alkyl internal acetylenes [130]. This reaction was initiated by reduction of the $\mathrm{C}-\mathrm{Br}$ bond which can generate a $\mathrm{C} s p^{3}$ radical, followed by radical addition and cyclization cascade to give the corresponding quinolone derivatives in $76 \%$ to quant yields. When using $N$-(alkyl-2-yl-1-yl)-pyridin-2(1H)-ones as the substrates, products containing ring cores of camptothecins were obtained [131,132] (Scheme 23).

\subsection{Imidoyl radical or carbonyl radical precursors}

The imidoyl radical can be utilized in the photoinduced difunctionalization of alkynes. This strategy was often used in cyclization reactions. In 2014, Xiao and co-workers utilized $2 \mathrm{H}$-azirines as a source of imidoyl radicals to achieve a visible light induced formal [3+2] cycloaddition [133]. 2H-pyrroles are oxidized by excited state $\mathrm{PC}$ to give $\mathrm{PC}^{-}$and nitrogen centered radical cations, followed by a ring-opening process to afford imidoyl radicals. By this method, the highly functionalized pyr-

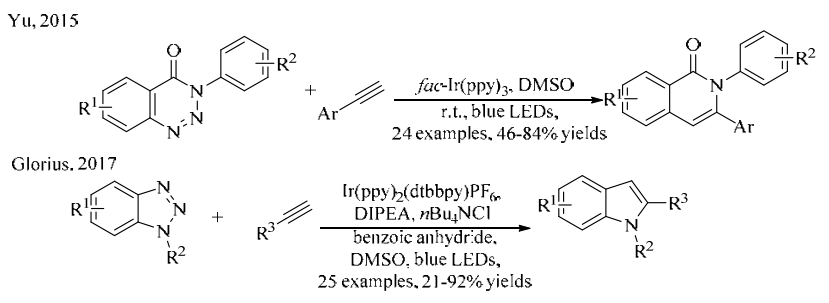

Scheme 20. Synthesis of isoquinolines or indoles via visible light induced denitrogenation.
Yuan, 2016

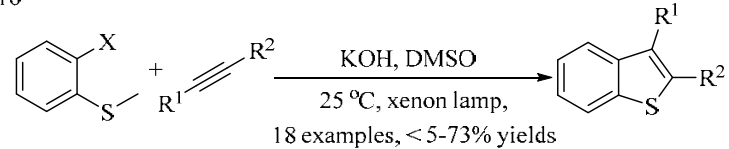

Scheme 21. Visible light promoted cyclization reaction with aryl halides.

roles were obtained in 31\%-98\% yields. It should be noted that they successfully carried out an unprecedented photocascade $[3+2]$ reaction; here, the $2 \mathrm{H}$-azirines were generated in situ via energy transfer process [134], followed by photoinduced redox-neutral [3+2] cycloaddition. Zhou and co-workers explored the visible light promoted synthesis of 2-trifluoromethyl quinolones [135] and trifluoromethyl indoles [136] (Scheme 24). In this methodology, imidoyl radicals were generated from $\mathrm{C}-\mathrm{Cl}$ bond cleavage by visible light photocatalysis.

In 2017, Zhang and Wang explored visible light induced acyarylation reactions. $\alpha$-Oxo-carboxylic acids were used as the radical sources, which could undergo decarboxylation to afford carbonyl radicals by iodide catalyst. The desired coumarins were obtained in 51\%-81\% yields [137]. Aryl aldehydes and aryl carbonyl chlorides could also be used as carbonyl radical precursors. 3-carbonyl coumarins [138,139] and 3-acylspiro[4,5]trienone [140] were obtained by photocatalysis (Scheme 25).

\section{Other heteroatom radical reagents}

The difunctionalization/heterocyclization of alkynes initiated via a hetero radical was a direct strategy to construct molecules containing a heteroatom with an unsaturated bond in which hetero-radicals(S/P/N/Se/Br/O) were generated via photocatalysis.

\subsection{Nitrogen radical reagents}

In 2016, Belmont and Brachet reported the visible light amination/Smiles cascade reaction of benzenesulfonohydrazone [141]. Using $\mathrm{Ru}(\mathrm{bpy}){ }_{3} \mathrm{Cl}_{2} \cdot 2 \mathrm{H}_{2} \mathrm{O}$ as a photocatalyst, 1.5
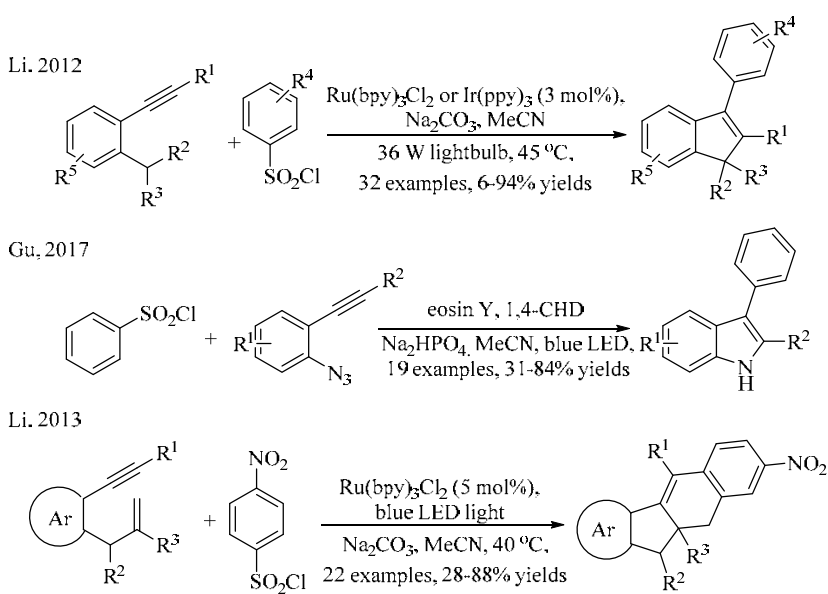

Scheme 22. Visible light induced arylative cyclization reactions with aryl sulfonyl chlorides. 


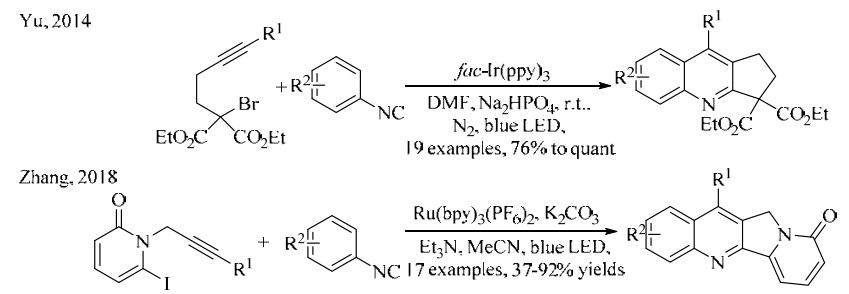

Scheme 23. Visible light promoted synthesis of quinolone derivatives using phenyl isocyanides.

equivalents of $\mathrm{NaOH}$, and $3 \AA$ molecular sieves, benzenesulfonohydrazones were transformed into the corresponding phthalazines in 30\%-83\% yields. In addition, these reactions could also be accomplished in a sequential one-pot process with similar outcomes. In this process, benzenesulfonohydrazones were generated by the corresponding hydrazides and aldehydes. In 2017, Wang and co-workers explored a visible light induced synthesis of oxazoles using $2 \mathrm{H}$-azirines as nitrogen radical precursors [142] (Scheme 26). They identified that the oxidation ability of II was strong enough to oxidize $2 \mathrm{H}$-azirines to afford nitrogen radical cations.

\subsection{Phosphorus radical reagents}

In 2015, Cai and co-workers explored a methodology to synthesize $\beta$-ketophosphine oxides via visible light promoted oxidative phosphinylation of aryl alkynes [143]. With rhodamine $\mathrm{B}$ as a photocatalyst, in the presence of white LEDs, aryl alkynes and diarylphosphine oxides were transformed into various $\beta$-ketophosphine oxides in $64 \%-94 \%$ yields (Scheme 27). In this route, phosphorus centered radicals were generated through oxidation of excited state photocatalyst and deprotonation cascade.

A visible light driven oxidative $\mathrm{C}-\mathrm{H} / \mathrm{P}-\mathrm{H}$ functionalization reaction of secondary phosphine oxides with alkynes was reported by Lakhdar and co-workers in 2016 [144]. Dia-

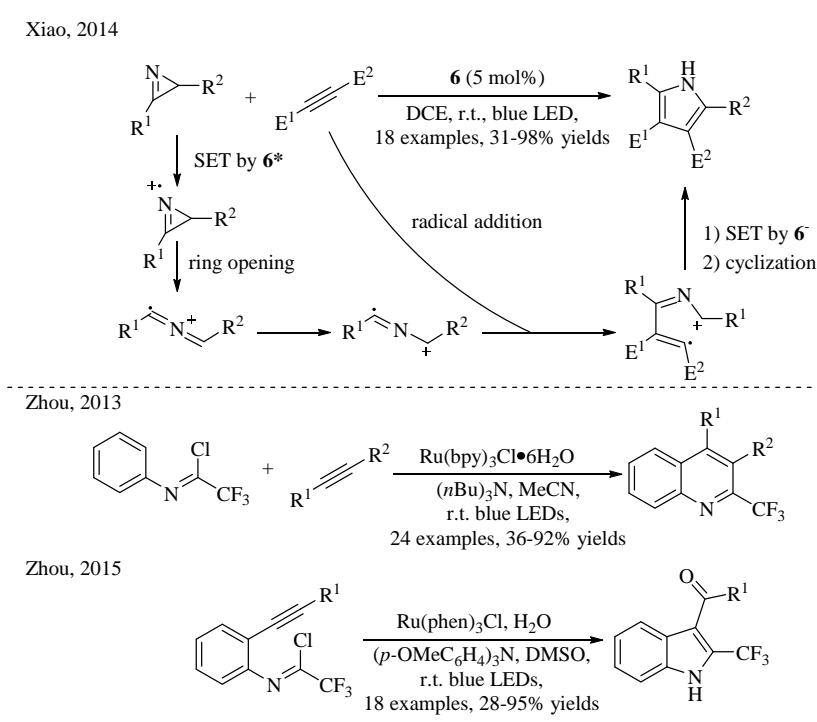

Scheme 24. Visible light promoted difunctionalization reactions with imidoyl radicals.

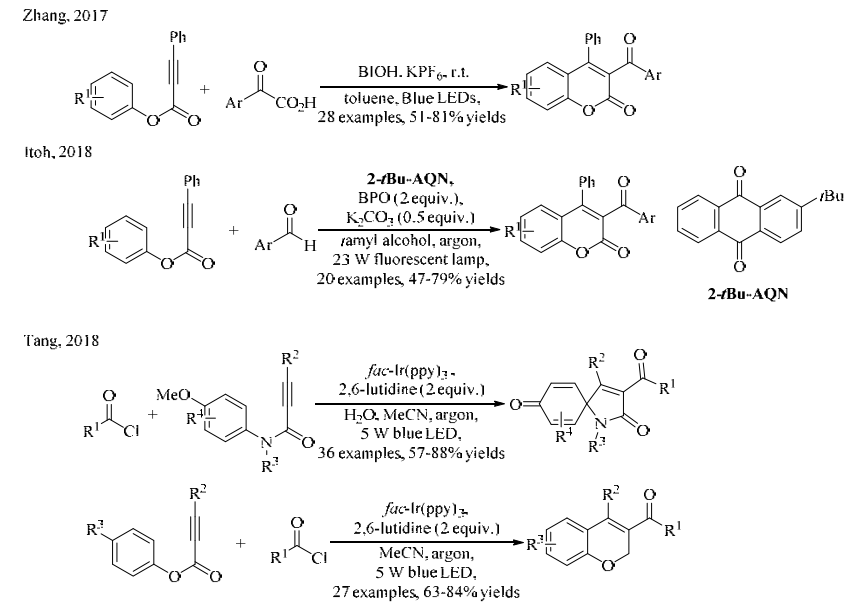

Scheme 25. Visible light induced acylcyclization reactions.

rylphosphine oxides reacted with internal alkynes to give the benzo[ $b]$ phosphole oxides in $43 \%-91 \%$ yields using eosin $\mathrm{Y}$ as photocatalyst, $\mathrm{N}$-ethyloxy-2-methylpyridinium tetrafluoroborate as oxidant, and $\mathrm{NaHCO}_{3}$ as base, under irradiation by green LED. It should be noted that phosphorus centered radicals were obtained by hydrogen abstraction of ethoxy radical, which was generated from the EDA-complex decomposition via visible light. Similar strategies could be used for photoinduced syntheses of 3-phosphorylated coumarins [145] and phosphorylated quinones [146] (Scheme 28).

\subsection{Sulfur/selenium radical reagents}

The Wang group in 2015 carried out an initiative reaction employing eosin $\mathrm{Y}$ as a photocatalyst, 1 equivalent of tert-butyl hydroperoxide as an oxidant, and $\mathrm{MeCN} / \mathrm{H}_{2} \mathrm{O}(1 / 1)$ as the solvent, under visible light irradiation at room temperature to achieve the arylsulfonylation of alkynes with arylsulfinic acids [147]. The sulfonyl radicals were generated by hydrogen abstraction of tertbutoxyl radical which were obtained by reduction of photoexcited eosin Y. By this method, the arylsulfonylation products were obtained in 55\%-77\% yields. In 2017, a similar method was utilized to synthesize 3-sulfonyl azaspiro[4,5] trienones by Wang and Wei [148]. In addition, sulfonyl radicals were also obtained by decomposition of the corresponding EDA complexes under visible light irradiation to achieve the synthesis of polyfunctionalized phenanthridines [149] (Scheme 29).

Sulfonyl radicals can also be generated by the decomposition of sulfonyl derivatives via visible light photocatalysis. In

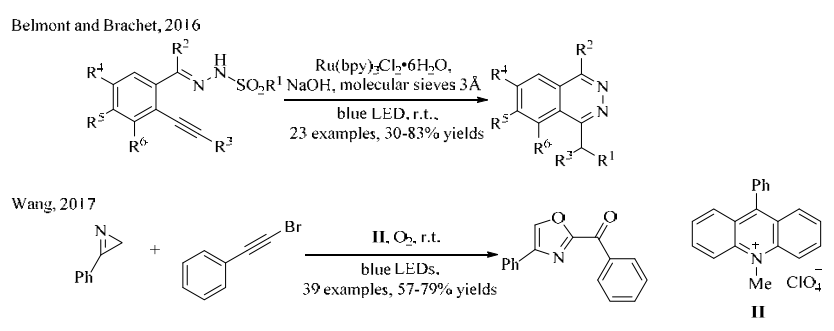

Scheme 26. Visible light induced amination reactions with alkynes. 


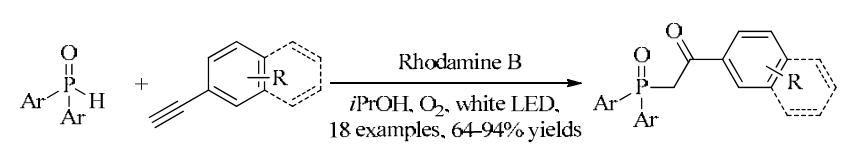

Scheme 27. Visible light induced synthesis of $\beta$-ketophosphine oxides.

2016, Cai and co-workers achieved a visible light promoted oxysulfonylation of alkynes [150]. In this transformation, sulfonyl hydrazides were used as the sulfonyl radical precursors; $\mathrm{Ni}$, Niu [151] and Song [152] utilized sulfonyl chlorides to achieve visible light promoted oxysulfonylation and sulfonyl cyclization reactions, respectively. Single electron transfer of sodium sulfinate salts under irradiation of visible light could also take place to generate sulfonyl radicals, which was explored by Kshirsagar and co-workers to synthesize 3-sulfonylindoles [153].

Apart from the methods mentioned above, sulfonyl radicals were also generated by radical insertion of sulfur dioxide. In 2018, Manolikakes and co-workers explored visible light induced synthesis of 3-aryl sulfonyl courmains without photocatalyst. In this process, the charge transfer species, which were generated from diaryliodonium salts and DABSO, could undergo a photoinduced decomposition process to give aryl radicals. Sulfur dioxide insertion occurred to afford the corresponding aryl sulfonyl radicals [154] (Scheme 30).

Other types of thiyl radicals have also been used in the visible light promoted difunctionalization of alkynes. Diphenyldisulfides and thiophenols were often used as thinly radical precursors. In 2016, Wang and Li explored the visible light induced synthesis of $\alpha$-diketone using thiyl radical as a catalyst [155]. The thiyl radical generated from diphenyldisulfide could undergo a radical addition to the alkynes. The $\mathrm{O}_{2}$ abstraction afforded the peroxy radical species. The intramolecular radical addition could regenerate the thiyl radical. A similar strategy for the generation of thiyl radicals was applied to synthesize benzothiophenes under visible light irradiation without photocatalysts [156]. In addition, thiyl radicals generated from thiophenols have also been utilized in cyclization reactions of alkynes [157].

Very recently, Kshirsagar and co-workers explored the visible light promoted synthesis of 3-thiocyanatobenzothiophenes [158] (Scheme 31). In this process, the thiyl radical was gener-

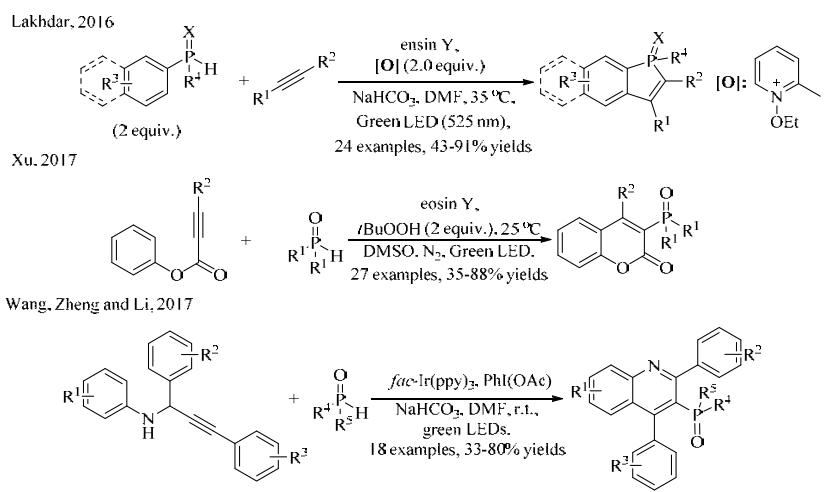

Scheme 28. Visible light induced cyclization reactions of alkynes with phosphine oxides.

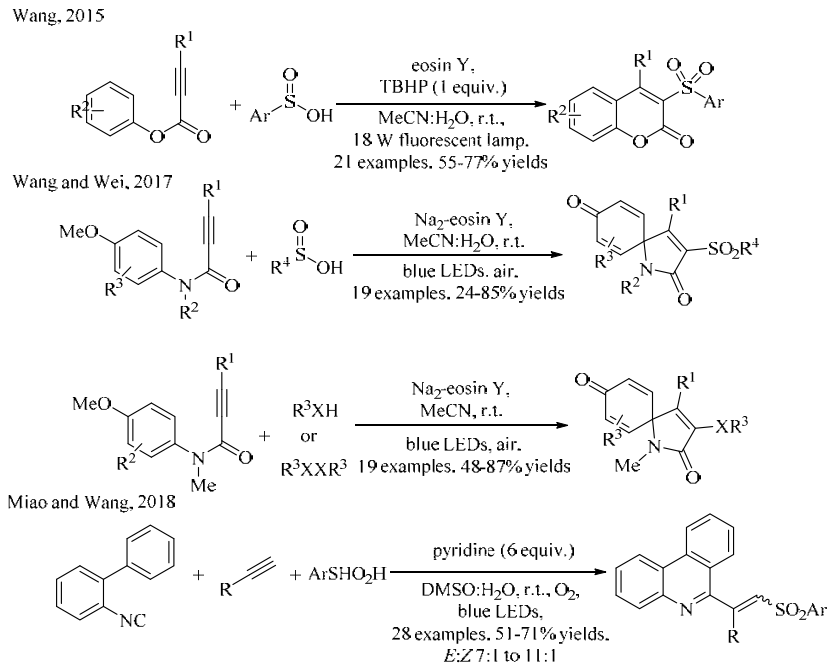

Scheme 29. Visible light induced arylsulfonylation of alkynes with aryl sulfinic acids.

ated from the oxidation of ammonium salt of thiocyanate by visible light photocatalysis.

\subsection{Bromo radical reagent}

In 2017, She and co-workers explored a methodology to synthesize 3-bromocoumarins via visible light photocatalysis. The bromo radical was generated from $N$-bromobutanimide under irradiation by blue LEDs with the assistance of tetrahydrofuran. The corresponding bromo radical reacted with alkynoates to afford the expected products in $40 \%-75 \%$ yields [159] (Scheme 32).

\subsection{Oxygen radical reagent}

In 2015, Wille and König achieved the visible light mediated synthesis of benzil with diphenylacetylene [160] (Scheme 33). Using Acr+-Mes 6 as a photocatalyst, under irradiation by blue

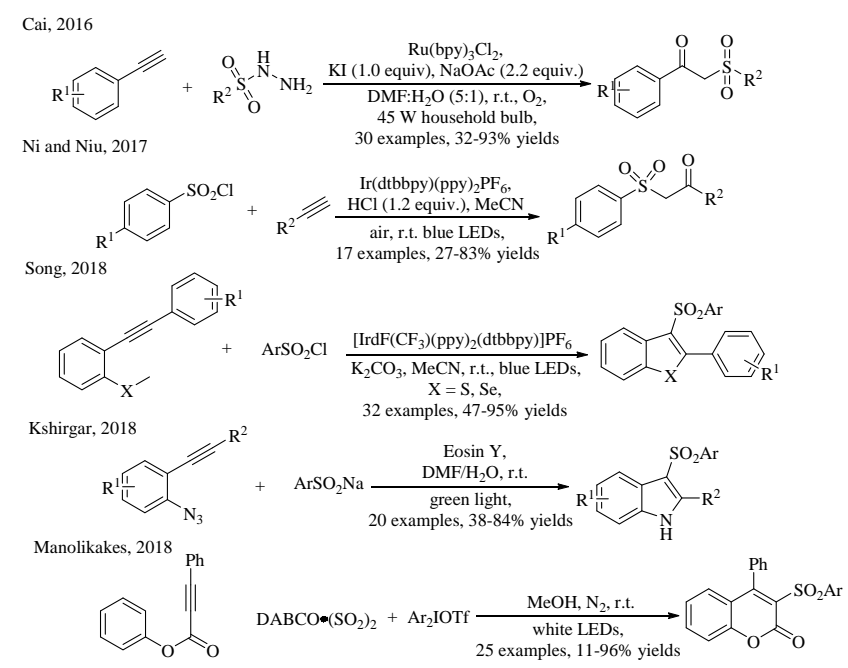

Scheme 30. Photocatalytic difunctionalization reactions with sulfonyl derivatives. 


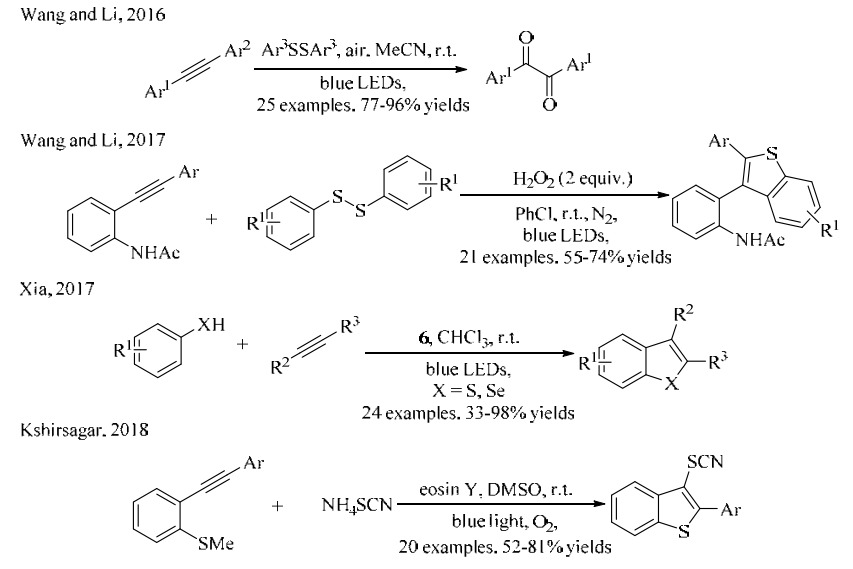

Scheme 31. Photoinduced difunctionalization of alkynes with different thiyl radical precursors.

LEDs, benzil was obtained in $32 \%$ yield. In this process, a nitrate radical was generated by photocatalysis. However, the generation of benzophenone could not be avoided in this transformation.

\section{Organometallic reagents}

Transition metal catalysis could be one of the most efficient methods to obtain difunctionalized alkynes. The high regio- and stereoselectivity could be achieved by the rational design of ligands. However, strong oxidants might be needed in some reactions, which could result in the limitation of substrate scope and reduced atom-economy [161-167]. To avoid such disadvantages, strong oxidation or reduction abilities in mild conditions generated by photocatalysis could be much more favorable. So far, transition metal and photocatalyst co-catalyzed methodologies have flourished in recent years, and have been widely used in $\mathrm{C}-\mathrm{H}$ functionalization and decarbofunctionalization reactions [168-170].

Gold and photocatalyst co-catalyzed arylfunctionalization reactions of alkynes have been reported in recent years. Organo gold reagents were often used as carbophilic Lewis acids, which could be coordinated to alkynes, followed by a nucleophilic attack to generate new $\mathrm{C}-\mathrm{Au}$ and $\mathrm{C}-\mathrm{Nu}$ bonds. The strategy could be based on the $\mathrm{Au}^{\mathrm{I}} / \mathrm{Au}^{\mathrm{III}}$ catalytic cycle. The $\mathrm{Au} / \mathrm{Au}{ }^{\mathrm{III}}$ couple was $+1.41 \mathrm{~V}[171,172]$, which meant that strong oxidants were needed for this transformation. Meanwhile, the oxidative quenching cycle of $\mathrm{PC}$ could oxidize $\mathrm{Au}^{\mathrm{II}}$ species under mild conditions. In 2016, Shin and co-workers achieved the gold and Ru photocatalyst co-catalyzed Meyer-Schuster rearrangement reaction of alkynes [173] (Scheme 34). Utilizing $\mathrm{Ph}_{3} \mathrm{PAuCl}$ and $\mathrm{Ru}(\mathrm{bpy})_{3}{ }^{2+}$ as catalysts, under exposure to blue LEDs, secondary or tertiary propargyl alcohols reacted with aryldiazonium salts to afford $\alpha$-aryl substituted<smiles></smiles>

Scheme 32. Photomediated bromocyclization of alkynoates.

König. 2015

$$
\mathrm{LiNO}_{3} \frac{\mathrm{G.O}_{2}}{455 \mathrm{~nm} L \mathrm{LEDs}, \mathrm{MeCN}} \prod_{\mathrm{O}}^{\mathrm{Ph}}+\left.\right|_{32 \% \text { yields }} ^{\mathrm{Ph}}
$$

Scheme 33. Photomediated synthesis of benzil.

$\alpha, \beta$-unsaturated ketones in 35\%-95\% yields. It should be noted that the $E / Z$ ratio was determined by the photostationary equilibrium of products. In the same year, a similar transformation was also achieved by the Alcaide, Almendros [174], and Glorius groups [175].

When TMS-terminated alkynols were used as substrates, the corresponding tri- and tetra-substituted $\alpha, \beta$-unsaturated ketones were obtained. A similar strategy was followed in the photoinduced synthesis of 2,3-diarylbenzofuran with 2-(trimethylsilyl) ethynyl phenols [176]. In this process, carbon $(s p)$ arylation of TMS-terminated alkynes could take place first to yield internal phenyl alkynes, which could undergo a gold and photocatalyst co-catalyzed process. This strategy could be utilized in the synthesis of hetero cycles, which was explored by Alcade and Almendros [177].

In the same year, Ollivier and Fensterbank also utilized a similar gold and photoredox system to achieve arylative cyclization reactions [178] (Scheme 35). Benzofuran derivatives were obtained from $o$-alkynylphenols and aryldiazonium salts in $6 \%-86 \%$ yields. This strategy could be utilized in visible light initiated synthesis of multi-substituted indoles [179], spirocarbocycles [180], enantioenriched 2,3-dihydropynoles [181], and other compounds [182] (Scheme 36). It should be noted that visible light induced transition metal catalyzed difunctionalization of alkynes could take place without a photocatalyst. In this case, the organometallic complex acted simultaneously as a photosensitizer and an activator of alkynes. In 2015, Hwang and co-workers explored a visible light induced copper-catalyzed $\mathrm{C}-\mathrm{H}$ annulation of arylamines with terminal alkynes and benzoquinones [183]. In this process, the copper(I) phenylacetylide species absorbed visible light. A similar strategy was explored by the same group, using ynamides or ynamines instead of terminal alkynes [184]. In 2016, Hashmi reported the visible light mediated gold catalyzed aryl oxylation of alkynes [185]. Wong and co-workers also reported a similar method to synthesize quinoliziums [186] (Scheme 37). The DFT study of Hashmi's work revealed that the complex generated from gold(I) and aryldiazonium salt absorbed visible light leading to electron transfer between the two moieties [187]. In this process, reductive elimination was the rate determining step.

Very recently, $\mathrm{Wu}$ and co-workers achieved a visible light

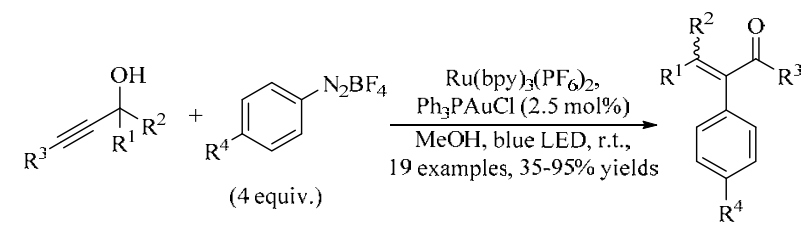

Scheme 34. Gold and photocatalyst co-catalyzed arylfunctionalization of alkynes. 


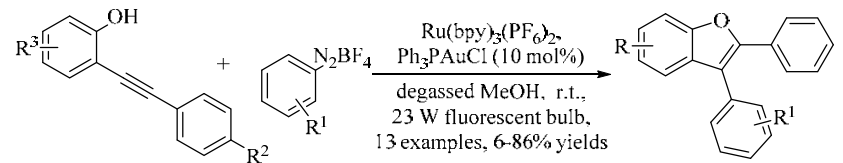

Scheme 35. Gold-catalyzed arylative cyclization of $o$-alkynylphenols via visible light catalysis.

promoted cobalt-carboxylation/acyl migration cascade reaction [188] (Scheme 38). The ortho-ester substituted aryl alkynes were transformed into $\gamma$-hydroxybutenolides in $20 \%-73 \%$ yields utilizing $\mathrm{CoBr}_{2}$ as a catalyst, in the presence of $\operatorname{Ir}(\mathrm{ppy})_{2}(\mathrm{dtbbpy})\left(\mathrm{PF}_{6}\right)$ under irradiation by blue LEDs. Remarkably, when using 2,6-bisalkynyl phenyl acetate as starting materials, $\gamma$-hydroxybutenolides with a benzofuran moiety were obtained in $40 \%-56 \%$ yields. The $\mathrm{Co}^{\mathrm{I}}$ species was generated upon reduction of $\mathrm{Co}^{\mathrm{II}}$ species by $\mathrm{Ir}^{\mathrm{II}}$ photocatalyst. The $\mathrm{Co}^{\mathrm{I}}$ species could undergo cyclometalation reaction with $\mathrm{CO}_{2}$ and alkynes. The intramolecular reaction of the five-membered cobaltacycle intermediate afforded the carbo-carboxylation intermediate. After reduction and transmetalation with $\mathrm{ZnBr}$, the $\mathrm{Co}^{\mathrm{I}}$ species were regenerated. Next, tautomerization of the $\mathrm{Zn}$ intermediates occurred to generate a $\gamma, \gamma$-keto acrylic zinc species. After further tautomerization, corresponding $\gamma$-hydroxybutenolides were obtained (Scheme 39).

\section{Other reagents}

1,3-dipole reagent, which can undergo a [3+2] cycloaddition with alkynes to afford cyclization products, can be generated by visible light photocatalysis. In 2017, Singh's group utilized benzyl chlorides or 2-phenyloxiranes and $\mathrm{NaN}_{3}$ as 1,3-dipole precursors [189]. However, the reaction could also occur without photocatalyst and visible light to afford products in moderate yields. The strategy was followed to achieve visible

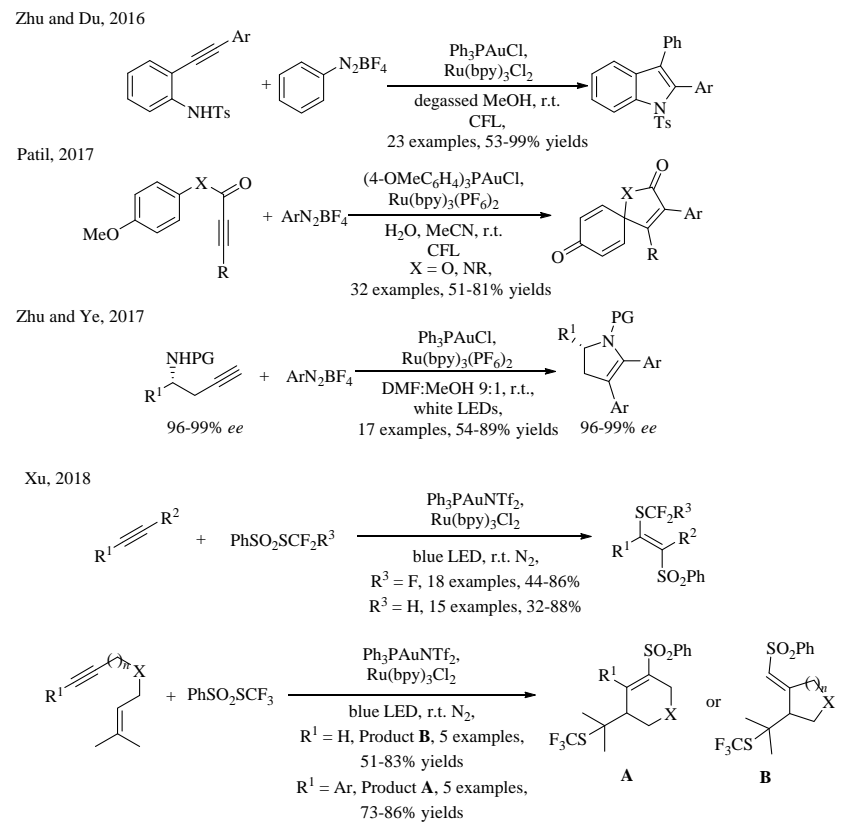

Scheme 36. Gold and photocatalyst co-catalyzed difunctionalization of alkynes.

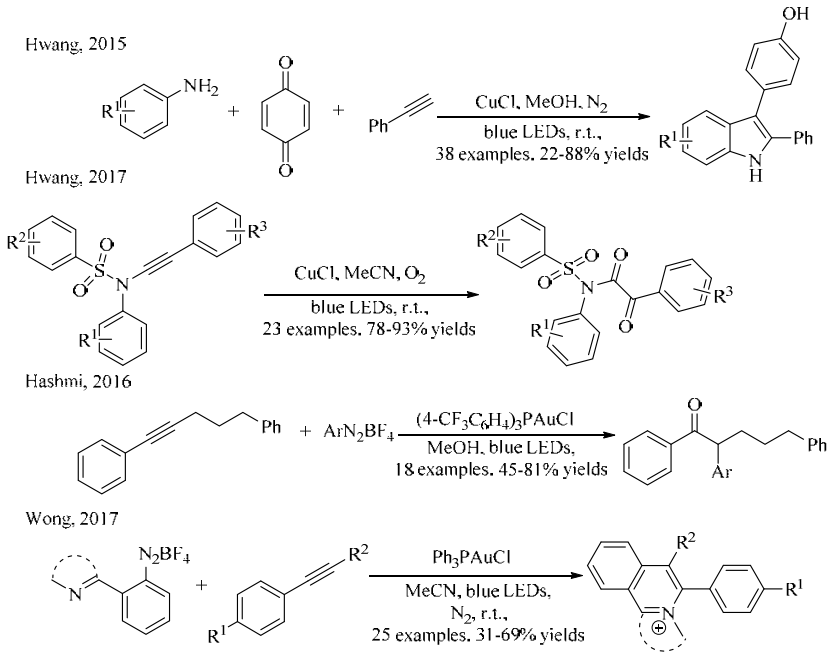

Scheme 37. Transition metal catalyzed difunctionalization of alkynes promoted by visible light.

light induced synthesis of 4-isoxazoline by using oxaziridine as substrate [190]. In this process, nitrone was generated by visible light photocatalysis. The oxaziridines were oxidized by photoexcited $6^{*}$. After a ring-opening process, the intermediates were reduced by $\mathbf{6}^{-}$to give the nitrones. These compounds could undergo a [3+2] cyclization reaction with alkynes to afford the desired products (Scheme 40).

The alkynyl radical could also trigger the alkyne difunctionalization reaction initiated by visible light. In 2018, Meng and Wang explored a visible light induced synthesis of $\alpha$-ketoamides with bromoalkynes and anilines [191]. The alkynyl radical was generated by the photodecomposition of bromo alkynes. After radical abstraction of oxygen, a coupling process with nitrogen radical occurred, followed by a rearrangement process to give the desired products.

Alkynes could also be oxidized by PC to achieve a difunctionalization reaction. This would require that the oxidative potential of the visible light photocatalyst is strong (the reductive potential of alkynes was $+2.163 \mathrm{~V}$ ). Liang and his co-worker achieved a visible light induced synthesis of 1,4-enediones [192]. Wang and Meng explored [2+2+2] cyclization of alkynes via visible light catalysis [193] (Scheme 41). These two methods provided a new direction for visible light promoted difunctionalization of alkynes.

\section{Conclusions and prospects}

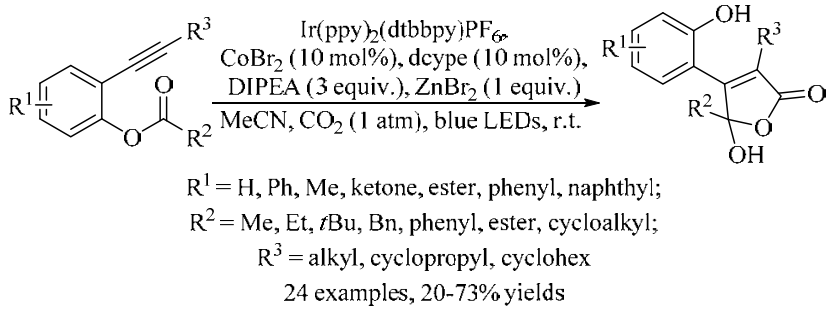

Scheme 38. Cobalt and photocatalyst co-catalyzed synthesis of $\gamma$-hydroxybutenolides. 


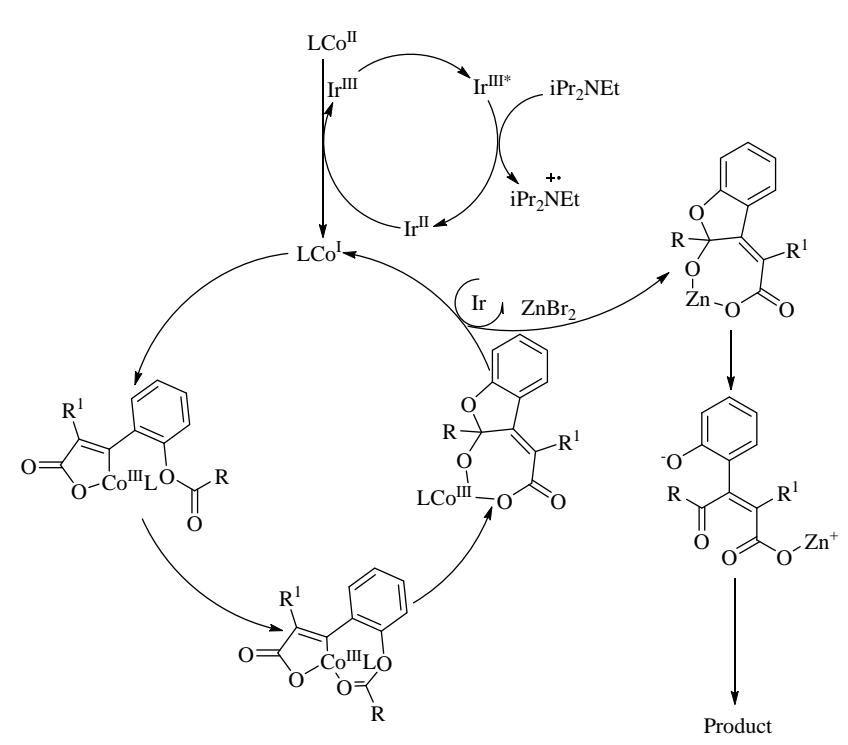

Scheme 39. Mechanism of cobalt and photocatalyst co-catalyzed synthesis of $\gamma$-hydroxybutenolides.

In this review, we have summarized visible light induced difunctionalization reactions of alkynes in which various recent significant advances are presented, particularly for organic synthesis.

Due to the powerful redox ability of visible light photocata- lysts, the radical strategy is one of the most preferred to achieve difunctionalization. A variety of useful skeletons have been obtained by these methods. However, generally, internal alkynes and aliphatic alkynes cannot be efficiently transformed into the corresponding products, and more efforts are needed to promote the regio- and stereoselectivity. In order to understand these kinds of reactions, more data and mechanistic studies are essential. 1,3-Dipole derivatives can be generated via visible light photocatalysis for the synthesis of heterocycles. However, these methods are limited by particular types of precursors. In addition, the single electron oxidation of alkynes can be utilized in visible light promoted difunctionalization of alkynes, which provides a new direction for alkyne difunctionalization. However, to overcome the high reductive potential of alkynes, the design of new visible light absorbing catalysts for these transformations is necessary.

Visible light induced transition metal catalyzed difunctionalization of alkynes has also been developed in recent years. In these cases, terminal alkynes and internal alkynes could be transformed into the desired products with high regioselectivity. However, several challenges still remain. For instance, the reactions of aliphatic alkynes are still not efficient. Moreover, high stereoselectivity still needs to be achieved. The earth abundant transition metals, such as iron, cobalt, and nickel, are ideal candidates for use in these transformations to meet the need for green chemistry.

Singh, 20.7

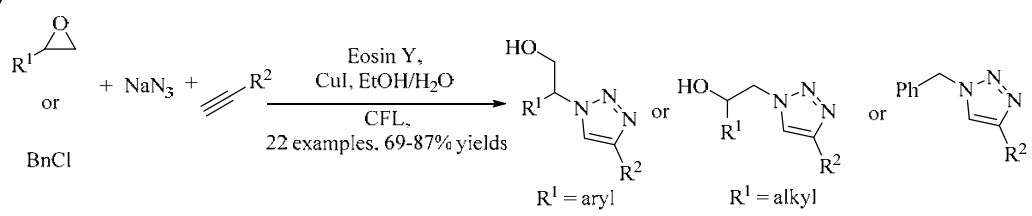

Woo. 2017

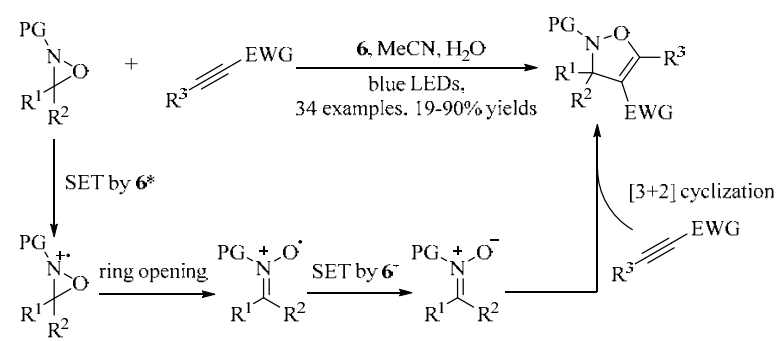

Scheme 40. Visible light induced [3+2] cyclization with alkynes.

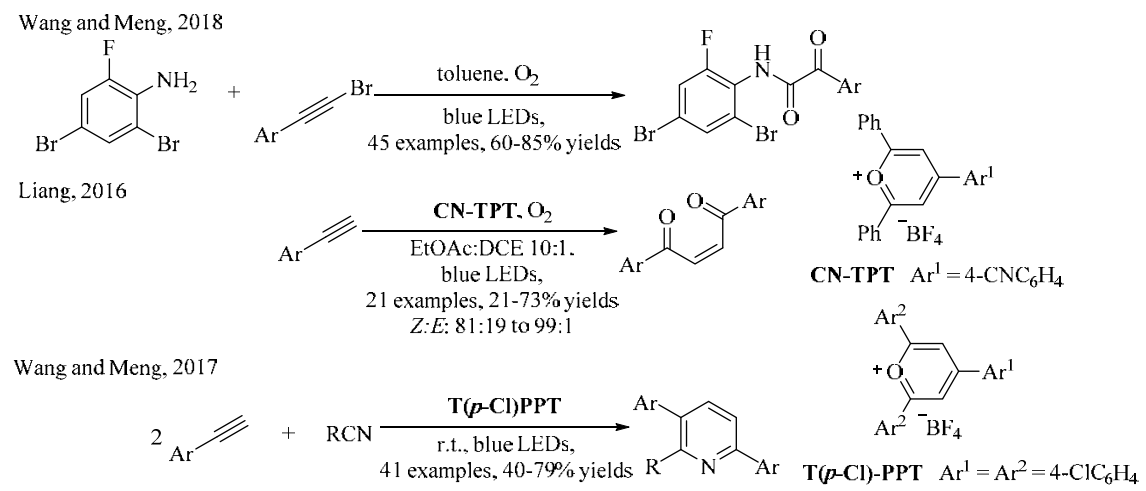

Scheme 41. Transformation of alkynes induced by visible light. 
Overall, we hope that this review is an informative tool to develop visible light induced alkyne difunctionalization reactions. We strongly believe that the unique reaction processes and mild conditions can provide inspiration and guidance for future investigations.

\section{Acknowledgments}

We were particularly grateful to Mr. Biao Cheng, Mr. Jun Guo, Mr. Xuzhong Shen, Mr. Qihang Guo and Mr. Peng Lu in our lab for their assistant in the correction of the manuscript.

\section{References}

[1] D. Habrant, V. Rauhala, A. M. P. Koskinen, Chem. Soc. Rev., 2010, 39, 2007-2017.

[2] J. P. Brand, J. Waser, Chem. Soc. Rev., 2012, 41, 4165-4179.

[3] F. Diederich, P. J. Stang, R. R. Tykwinski ed., Acetylene Chemistry: Chemistry, Biology and Material Science, Wiley-VCH, Weinheim, 2005.

[4] R. Gleiter, D. B. Werz, Chem. Rev., 2010, 110, 4447-4488.

[5] S. K. De, R. A. Gibbs, Synthesis, 2005, 1231-1233.

[6] N. P. Artemova, L, E. Nikitina, D. A. Yushkov, O. G. Shigabutdinova, V. V. Plemenkov, V. V. Klochkov, B. I. Khairutdinov, Chem. Nat. Compd., 2005, 41, 45-47.

[7] M. K. Potdar, S. S. Mohile, M. M. Salunkhe, Tetrahedron Lett., 2001, 42, 9285-9287.

[8] S. Sethna, R. Phadke, Org. React., 1953, 7, 1-58.

[9] T. D. A. Fernandes, B. G. Vaz, M. N. Eberlin, A. J. M. de Silva, P. R. R. Costa, J. Org. Chem., 2010, 75, 7085-7091.

[10] D. Giguère, R. Patnam, J. M. Juarez-Ruiz, M. Neault, R. Roy, Tetrahedron Lett., 2009, 50, 4254-4257.

[11] T. D. Fernandes, R. D. C. Carvalho, T. M. D. Goncalves, A. J. M. da Silva, P. R. R. Costa, Tetrahedron Lett., 2008, 49, 3322-3325.

[12] F. Ulgheri, M. Marchetti, O. Piccolo, J. Org. Chem., 2007, 72, 6056-6059.

[13] G. Battistuzzi, S. Cacchi, I. De Salve, G. Fabrizi, L. M. Parisi, Adv. Synth. Catal., 2005, 347, 308-312.

[14] I. T. Hwang, S. A. Lee, J. S. Hwang, K. I. Lee, Molecules, 2011, 16, 6313-6321.

[15] D. C. Dittmer, Q. Li, D. V. Avilov, J. Org. Chem., 2005, 70, $4682-4686$.
[16] H. Hong, N. Neamati, S. Wang, M. C. Nicklaus, A. Mazumder, H. Zhao, T. R. Burke, Y. Pommier, G. W. A. Milne, J. Med. Chem., 1997, 40, 930-936.

[17] D. N. Shah, N. M. Shah, J. Am. Chem. Soc., 1955, 77, 1699-1700.

[18] N. S. Belavagi, N. Deshapande, M. G. Sunagar, I. A. M. Khazi, RSC Adv., 2014, 4, 39667-39671.

[19] I. Yavari, R. Hekmat-Shoar, A. Zonouzi, Tetrahedron Lett., 1998, 39, 2391-2392.

[20] T. Harayama, K. Nakatsuka, H. Nishioka, K. Murakami, N. Hayashida, H. Ishii, Chem. Pharm. Bull., 1994, 42, 2170-2173.

[21] Y. Y. Liu, E. Thom, A. A. Liebman, J. Heterocycl. Chem., 1979, 16, 799-801.

[22] N. S. Narasimhan, F. S. Mali, M. V. Barve, Synthesis, 1979, 906-909.

[23] M. Q. Yang, N. Zhang, M. Pagliaro, Y. J. Xu, Chem. Soc. Rev., 2014, 43, 8240-8254.

[24] M. Q. Yang, Y. J. Xu, Phys. Chem. Chem. Phys., 2013, 15, 19102-19118.

[25] N. Zhang, M. Q. Yang, Z. R. Tang, Y. J. Xu, ACS Nano, 2014, 8, 623-633.

[26] Y. H. Zhang, N. Zhang, Z. R. Tang, Y. J. Xu, Chem. Sci., 2012, 3, 2812-2822.

[27] A. Fujishima, K. Honda, Nature, 1972, 238, 37-38.

[28] H. Kato, K. Asakura, A. Kudo, J. Am. Chem. Soc., 2003, 125, 3082-3089.

[29] T. K. Townsend, N. D. Browning, F. E. Osterloh, Energy Environ. Sci., 2012, 5, 9543-9550.

[30] X. Wang, Q. Xu, M. Li, S. Shen, X. Wang, Y. Wang, Z. Feng, J. Shi, H. Han, C. Li, Angew. Chem. Int. Ed., 2012, 51, 13089-13092.

[31] A. T. Garcia-Esparza, D. Cha, Y. Ou, J. Kubota, K. Domen, K. Takanabe, ChemSusChem, 2013, 6, 168-181.

[32] M. Grätzel, Acc. Chem. Rev., 1981, 14, 376-384.

[33] T. J. Meyer, Acc. Chem. Rev., 1989, 22, 163-170.

[34] H. Takeda, O. Ishitani, Coord. Chem. Rev., 2010, 254, 346-354.

[35] G. Ciamician, Science, 1912, 36, 385-394.

[36] T. P. Yoon, M. A. Ischay, J. Du, Nat. Chem., 2010, 2, 527-532.

[37] J. M. R. Narayanam, C. R. J. Stephenson, Chem. Soc. Rev., 2011, 40, 102-113.

[38] F. Teplý, Collect. Czech. Chem. Commun., 2011, 76, 859-917.

[39] J. Xuan, W. J. Xiao, Angew. Chem. Int. Ed., 2012, 51, 6828-6838.

[40] L. Shi, W. J. Xia, Chem. Soc. Rev., 2012, 41, 7687-7697.

[41] T. P. Yoon, ACS Catal., 2013, 3, 895-902.

[42] Y. M. Xi, H. Yi, A. W. Lei, Org. Biomol. Chem., 2013, 11, 2387-2403.

[43] M. N. Hopkinson, B. Sahoo, J. L. Li, F. Glorious, Chem. Eur. J., 2014,

\section{Graphical Abstract}

Chin. J. Catal., 2019, 40: 1003-1019 doi: S1872-2067(19)63278-X

Visible light promoted difunctionalization reactions of alkynes

Xiang Ren, Zhan Lu*

Zhejiang University

Visible light promoted difunctionalization and cyclization of alkynes are discussed. The strategy has succeeded in the construction of $\mathrm{C}-\mathrm{C}, \mathrm{C}-\mathrm{O}, \mathrm{C}-\mathrm{P}, \mathrm{C}-\mathrm{N}, \mathrm{C}-\mathrm{S}, \mathrm{C}-\mathrm{Se}$, and $\mathrm{C}-\mathrm{Br}$ bonds, as well as several valuable chemical skeletons under mild conditions.

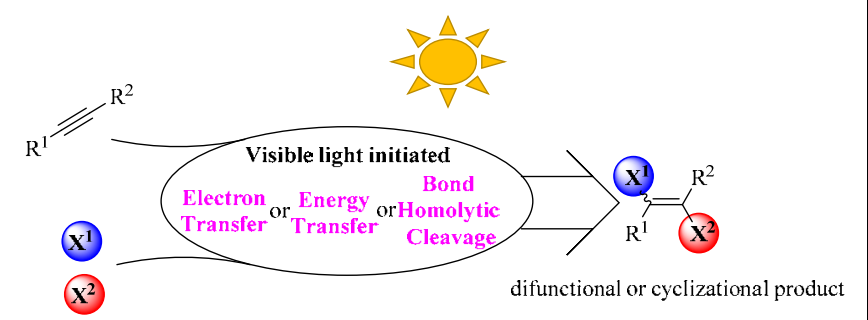

difunctional or cyclizational product 
20, 3874-3886.

[44] D. M. Schultz, T. P. Yoon, Science, 2014, 343, 1239176.

[45] L. Furst, J. M. R. Narayanam, C. R. J. Stephenson, Angew. Chem. Int. Ed., 2011, 50, 9655-9659.

[46] M. E. Weiss, L. M. Kreis, A. Lauber, E. M. Carreira, Angew. Chem. Int. Ed., 2011, 50, 11125-11128.

[47] M. E. Weiss, E. M. Carreira, Angew. Chem. Int. Ed., 2011, 50, 11501-11505.

[48] J. W. Beatty, C. R. J. Stephenson, J. Am. Chem. Soc., 2014, 136, 10270-10273.

[49] C. F. Wang, Z. Lu, Org. Chem. Front., 2015, 2, 179-190.

[50] B. P. Fors, C. J. Hawker, Angew. Chem. Int. Ed., 2012, 51, 8850-8853.

[51] G. M. Miyake, J. C. Theriot, Macromolecules, 2014, 47, 8255-8261.

[52] C. K. Prier, D. A. Rankic, D. W. C. MacMillan, Chem. Rev., 2013, 113, 5322-5363.

[53] N. A. Romero, D. A. Nicewicz, Chem. Rev., 2016, 116, 10075-10166.

[54] W. J. Yoo, T. Tsukamoto, S. Kobayashi, Org. Lett., 2015, 17, 3640-3642.

[55] D. R. Heitz, J. C. Tellis, G. A. Molander, J. Am. Chem. Soc., 2016, 138, 12715-12718.

[56] C. Cassani, G. Bergonzini, C.-J. Wallentin, Org. Lett., 2014, 16, 4228-4231.

[57] N. A. Romero, D. A. Nicewicz, J. Am. Chem. Soc., 2014, 136, 17024-17035.

[58] J. D. Griffin, M. A. Zeller, D. A. Nicewicz, J. Am. Chem. Soc., 2015, 137, 11340-11348.

[59] P. D. Morse, D. A. Nicewicz, Chem. Sci., 2015, 6, 270-274.

[60] M. Nappi, G. Bergonzini, P. Melchiorre, Angew. Chem. Int. Ed., 2014, 53, 4921-4925.

[61] J. Davies, S. G. Booth, S. Essafi, R. A. W. Dryfe, D. Leonori, Angew. Chem. Int. Ed., 2015, 54, 14017-14021.

[62] S. R. Kandukuri, A. Bahamonde, I. Chatterjee, I. D. Jurberg, E. C. Escudero-Adán, P. Melchiorre, Angew. Chem. Int. Ed., 2015, 54, 1485-1489.

[63] M. L. Spell, K. Deveaux, C. G. Bresnahan, B. L. Bernard, W. Sheffield, R. Kumar, J. R. Ragains, Angew. Chem. Int. Ed., 2016, 55, 6515-6519.

[64] J. Zhang, Y. Li, R. Xu, Y. Chen, Angew. Chem. Int. Ed., 2017, 56, 12619-12623.

[65] M. Parasram, V. Gevorgyan, Chem. Soc. Rev., 2017, 46, 6227-6240.

[66] M. Y. Cao, X. Ren, Z. Lu, Tetrehedron Lett., 2015, 56, 3732-3742.

[67] C. J. Wallentin, J. D. Nguyen, P. Finkbeiner, C. R. J. Stephenson, J. Am. Chem. Soc., 2012, 134, 8875-8884.

[68] N. Iqbal, J. Jung, S. Park, E. J. Cho, Angew. Chem. Int. Ed., 2014, 53, 539-542.

[69] G. B. Roh, N. Iqbal, E. J. Cho, Chin. J. Chem., 2016, 34, 459-464.

[70] K. Matsuzaki, T. Hiromura, H. Amii, N. Shibata, Molecules, 2017, 22, 1130.

[71] T. Yajima, M. Ikegami, Eur. J. Org. Chem., 2017, 2126-2129.

[72] X. Sun, Y. He, S. Yu, J. Photochem.Photobiol. A, 2018, 355, 326-331.

[73] T. Rawner, E. Lutsker, C. A. Kaiser, O. Reiser, ACS Catal., 2018, 8, 3950-3956.

[74] W. Fu, M. Zhu, G. Zou, C. Xu, Z. Wang, B. Ji, J. Org. Chem., 2015, 80, 4766-4770.

[75] Y. Li, Y. Lu, R. Mao, Z. Li, J. Wu, Org. Chem. Front., 2017, 4, 1745-1750.

[76] S. B. Nagode, A. K. Chaturvedi, N. Rastogi, Asian J. Org. Chem., 2017, 6, 453-457.

[77] Q. Deng, Y. Xu, P. Liu, L. Tan, P. Sun, Org. Chem. Front., 2018, 5, 19-23.
[78] Y. Xiang, Y. Li, Y. Kuang, J. Wu, Chem. Eur. J., 2017, 23, 1032-1035.

[79] R. Tomita, T. Koike, M. Akita, Angew. Chem., 2015, 127, 13115-13119.

[80] Y. Xiang, Y. Kuang, J. Wu, Org. Chem. Front., 2016, 3, 901-905.

[81] Y. R. Malpani, B. K. Biswas, H. S. Han, Y. S. Jung, S. B. Han, Org. Lett., 2018, 20, 1693-1697.

[82] H. S. Han, E. H. Oh, Y. S. Jung, S. B. Han, Org. Lett., 2018, 20, 1698-1702.

[83] H. S. Han, Y. J. Lee, Y. S. Jung, S. B. Han, Org. Lett., 2017, 19, 1962-1965.

[84] M. Zhu, W. Fu, Z. Wang, C. Xu, B. Ji, Org. Biomol. Chem., 2017, 15, 9057-9060.

[85] M. J. Bu, G. P. Lu, C. Cai, Catal. Commun., 2018, 114, 70-74.

[86] L. Chen, L. Wu, W. Duan, T. Wang, L. Li, K. Zhang, J. Zhu, Z. Peng, F. Xiong, J. Org. Chem., 2018, 83, 8607-8614.

[87] J. W. Tucker, C. R. J. Stephenson, Org. Lett., 2011, 13, 5468-5471.

[88] E. Arceo, E. Montroni, P. Melchiorre, Angew. Chem. Int. Ed., 2014, 53, 12064-12068.

[89] H. Jiang, Y. Cheng, Y. Zhang, S. Yu, Org. Lett., 2013, 15, 4884-4887.

[90] Z. G. Yuan, Q. Wang, A. Zheng, K. Zhang, L. Q. Lu, Z. Tang, W. J. Xiao, Chem. Commun., 2016, 52, 5128-5131.

[91] N. Zhou, J. Liu, Z. Yan, Z. Wu, H. Zhang, W. Li, C. Zhu, Chem. Commun., 2017, 53, 2036-2039.

[92] W. Zhang, C. Yang, Y. L. Pan, X. Li, J. P. Cheng, Org. Biomol. Chem., 2018, 16, 5788-5792.

[93] W. Dong, Y. Yuan, X. Gao, M. Keranmu, W. Li, X. Xie, Z. Zhang, Org. Lett., 2018, 20, 5762-5765.

[94] K. Wang, L. G. Meng, L. Wang, J. Org. Chem., 2016, 81, 7080-7087.

[95] L. A. Büldt, X. Guo, A. Prescimone, O. S. Wenger, Angew. Chem. Int. Ed., 2016, 55, 11247-11250.

[96] X. Gu, X. Li, Y. Qu, Q. Yang, P. Li, Y. Yao, Chem. Eur. J., 2013, 19, 11878-11882.

[97] Y. Shen, J. Cornella, F. Juliá-Hernández, R. Martin, ACS Catal., 2017, 7, 409-412.

[98] L. Wang, J. M. Lear, S. M. Rafferty, S. C. Fosu, D. A. Nagib, Science, 2018, 362, 225-229.

[99] H. G. Roth, N. A. Romero, D. A. Nicewicz, Synlett, 2016, 27, 714-723.

[100] A. Hu, J. J. Guo, H. Pan, H. Tang, Z. Gao, Z. Zuo, J. Am. Chem. Soc., 2018, 140, 1612-1616.

[101] A. Hu, J. J. Guo, H. Pan, Z. Zuo, Science, 2018, 361, 668-672.

[102] J. Ye, I. Kalvet, F. Schoenebeck, T. Rovis, Nat. Chem., 2018, 10, 1037-1041.

[103] G. J. Choi, Q. Zhu, D. C. Miller, C. J. Gu, R. R. Knowles, Nature, 2016, 539, 268-271.

[104] J. D. Cuthbertson, D. W. C. MacMillan, Nature, 2015, 519, 74-77.

[105] K. A. Margrey, W. L. Czaplyski, D. A. Nicewicz, E. J. Alexanian, J. Am. Chem. Soc., 2018, 140, 4213-4217.

[106] D. F. Chen, J. C. K. Chu, T. Rovis, J. Am. Chem. Soc., 2017, 139, 14897-14900.

[107] S. Mukherjee, B. Maji, A. Tlahuext-Aca, F. Glorius, J. Am. Chem. Soc., 2016, 138, 16200-16203.

[108] J. L. Jeffrey, J. A. Terrett, D. W. C. MacMillan, Science, 2015, 349, 1532-1536.

[109] S. Feng, X. Xie, W. Zhang, L. Liu, Z. Zhong, D. Xu, X. She, Org. Lett., 2016, 18, 3846-3849.

[110] A. Shao, X. Luo, C. W. Chiang, M. Gao, A. Lei, Chem. Eur. J., 2017, 23, 17874-17878.

[111] P. Zhang, T. Xiao, S. Xiong, X. Dong, L. Zhou, Org. Lett., 2014, 16, 3264-3267.

[112] X. F. Xia, G. W. Zhang, D. Wang, S. L. Zhu, J. Org. Chem., 2017, 82, 
8455-8463.

[113] F. Gao, C. Yang, N. Ma, G. L. Gao, D. Li, W. Xia, Org. Lett., 2016, 18, 600-603.

[114] Y. Li, B. Liu, R. J. Song, Q. A. Wang, J. H. Li, Adv. Synth. Catal., 2016, $358,1219-1228$.

[115] S. Jana, A. Verma, R. Kadu, S. Kumar, Chem. Sci., 2017, 8, 6633-6644

[116] Y. Liu, R. J. Song, S. Luo, J. H. Li, Org. Lett, 2018, 20, 212-215.

[117] M. H. Huang, Y. L. Zhu, W. J. Hao, A. F. Wang, D. C. Wang, F. Liu, P. Wei, S. J. Tu, B. Jiang, Adv. Synth. Catal., 2017, 359, 2229-2234.

[118] M. H. Huang, C. F. Zhu, C. L. He, Y. L. Zhu, W. J. Hao, D. C. Wang, S. J. Tu, B. Jiang, Org. Chem. Front., 2018, 5, 1643-1650.

[119] D. P. Hari, T. Hering, B. König, Org. Lett., 2012, 14, 5334-5337.

[120] T. Xiao, X. Dong, Y. Tang, L. Zhou, Adv. Synth. Catal., 2012, 354, 3195-3199.

[121] T. Chatterjee, D. S. Lee, E. J. Cho, J. Org. Chem., 2017, 82, 4369-4378.

[122] T. F. Niu, D. Y. Jiang, S. Y. Li, B. Q. Ni, L. Wang, Chem. Commun., 2016, 52, 13105-13108.

[123] W. Liu, C. Wang, L. Wang, Ind. Eng. Chem. Res., 2017, 56, 6114-6123.

[124] H. Wang, S. Yu, Org. Lett., 2015, 17, 4272-4275.

[125] M. Teders, L. Pitzer, S. Buss, F. Glorius, ACS Catal., 2017, 7, 4053-4056.

[126] L. Gao, B. Chang, W. Qiu, L. Wang, X. Fu, R. Yuan, Adv. Synth. Catal., 2016, 358, 1202-1207.

[127] J. D. Xia, G. B. Deng, M. B. Zhou, W. Liu, P. Xie, J. H. Li, Synlett, 2012, 23, 2707-2713.

[128] L. Gu, C. Jin, W. Wang, Y. He, G. Yang, G. Li, Chem. Commun., 2017, 53, 4203-4206.

[129] G. B. Deng, Z. Q. Wang, J. D. Xia, P. C. Qian, R. J. Song, M. Hu, L. B. Gong, J. H. Li, Angew. Chem. Int. Ed., 2013, 52, 1535-1538.

[130] X. Sun, J. Li, Y. Ni, D. Ren, Z. Hu, S. Yu, Asian J. Org. Chem., 2014, 3, $1317-1325$

[131] Y. Yuan, W. Dong, X. Gao, H. Gao, X. Xie, Z. Zhang, J. Org. Chem., 2018, 83, 2840-2846.

[132] Y. Yuan, W. Dong, X. Gao, X. Xie, D. P. Curran, Z. Zhang, Chin. J. Chem., 2018, 36, 1035 - 1040 .

[133] J. Xuan, X. D. Xia, T. T. Zeng, Z. J. Feng, J. R. Chen, L. Q. Lu, W. J. Xiao, Angew. Chem. Int. Ed., 2014, 53, 5653-5656.

[134] E. P. Farney, T. P. Yoon, Angew. Chem. Int. Ed., 2014, 53, 793-797.

[135] X. Dong, Y. Xu, J. J. Liu, Y. Hu, T. Xiao, L. Zhou, Chem. Eur. J., 2013, 19, 16928-16933.

[136] X. Dong, Y. Hu, T. Xiao, L. Zhou, RSC Adv., 2015, 5, 39625-39629.

[137] S. Yang, H. Tan, W. Ji, X. Zhang, P. Li, L. Wang, Adv. Synth. Catal., 2017, 359, 443-453.

[138] K. Kawaai, T. Yamaguchi, E. Yamaguchi, S. Endo, N. Tada, A. Ikari, A. Itoh, J. Org. Chem., 2018, 83, 1988-1996.

[139] Y. Liu, Q. L. Wang, C. S. Zhou, B. Q. Xiong, P. L. Zhang, S. J. Kang, C. A. Yang, K. W. Tang, Tetrahedron Lett., 2018, 59, 2038-2041.

[140] Y. Liu, Q. L. Wang, C. S. Zhou, B. Q. Xiong, P. L. Zhang, C. A. Yang, K. W. Tang, J. Org. Chem., 2018, 83, 2210-2218.

[141] E. Brachet, L. Marzo, M. Selkti, B. König, P. Belmont, Chem. Sci., 2016, 7, 5002-5006.

[142] L. Chen, H. Li, P. Li, L. Wang, Org. Lett., 2016, 18, 3646-3649.

[143] M. J. Bu, G. P. Lu, C. Cai, Catal. Sci. Technol,, 2016, 6, 413-416.

[144] V. Quint, F. Morlet-Savary, J. F. Lohier, J. Lalevée, A. C. Gaumont, S. Lakhdar, J. Am. Chem. Soc., 2016, 138, 7436-7441.

[145] D. Liu, J. Q. Chen, X. Z. Wang, P. F. Xu, Adv. Synth. Catal., 2017, 359, 2773-2777.

[146] Z. G. Wu, X. Liang, J. Zhou, L. Yu, Y. Wang, Y. X. Zheng, Y. F. Li, J. L.
Zuo, Y. Pan, Chem. Commun., 2017, 53, 6637-6640.

[147] W. Yang, S. Yang, P. Li, L. Wang, Chem. Commun., 2015, 51, $7520-7523$

[148] W. Wei, H. Cui, D. Yang, H. Yue, C. He, Y. Zhang, H. Wang, Green Chem., 2017, 19, 5608-5613.

[149] Y. Li, T. Miao, P. Li, L.Wang, Org. Lett., 2018, 20, 1735-1739.

[150] S. Cai, D. Chen, Y. Xu, W. Weng, L. Li, R. Zhang, M. Huang, Org. Biomol. Chem., 2016, 14, 4205-4209.

[151] T. Niu, D. Jiang, B. Ni, Tetrahedron Lett., 2017, 58, 4299-4303.

[152] J. Yan, J. Xu, Y. Zhou, J. Chen, Q. Song, Org. Chem. Front,, 2018, 5, $1483-1487$.

[153] R. S. Rohokale, S. D. Tambe, U. A. Kshirsagar, Org. Biomol. Chem., 2018, 16, 536-540.

[154] Z. Chen, N. W. Liu, M. Bolte, H. Ren, G. Manolikakes, Green Chem., 2018, 20, 3059-3070.

[155] X. Zhu, P. Li, Q. Shi, L. Wang, Green Chem., 2016, 18, 6373-6379.

[156] X. Xie, P. Li, Q. Shi, L. Wang, Org. Biomol. Chem., 2017, 15, 7678-7684.

[157] X. F. Xia, G. W. Zhang, S. L. Zhu, Tetrahedron, 2017, 73, $2727-2730$

[158] S. D. Tambe, M. S. Jadhav, R. S. Rohokale, U. A. Kshirsagar, Eur. J. Org. Chem., 2018, 4867-4873.

[159] S. Feng, J. Li, Z. Liu, H. Sun, H. Shi, X. Wang, X. Xie, X. She, Org. Biomol. Chem., 2017, 15, 8820-8826.

[160] T. Hering, T. Slanina, A. Hancock, U. Wille, B. König, Chem. Commun., 2015, 51, 6568-6571.

[161] L. T. Ball, G. C. Lloyd-Jones, C. A. Russell, J. Am. Chem. Soc., 2014, 136, 254-264.

[162] L. T. Ball, G. C. Lloyd-Jones, C. A. Russell, Science, 2012, 337, 1644-1648.

[163] T. de Haro, C. Nevado, Chem. Commun., 2011, 47, 248-249.

[164] G. Zhang, L. Cui, Y. Wang, L. Zhang, J. Am. Chem. Soc., 2010, 132, 1474-1475.

[165] W. E. Brenzovich, D. Benitez, A. D. Lackner, H. P. Shunatona, E. Tkatchouk, W. A. Goddard III, F. D. Toste, Angew. Chem. Int. Ed., 2010, 49, 5519-5522.

[166] W. Wang, J. Jasinski, G. B. Hammond, B. Xu, Angew. Chem. Int. Ed., 2010, 49, 7247-7252.

[167] A. Iglesias, K. Muňiz, Chem. Eur. J., 2009, 15, 10563-10569.

[168] J. Twilton, C. Le, P. Zhang, M. H. Shaw, R. W. Evans, D. W. C. MacMillan, Nat. Rev. Chem., 2017, 1, 0052.

[169] J. Wu, J. Li, H. Li, C. Zhu, Chin. J. Org. Chem., 2017, 37, 2203-2210.

[170] L. Ruan, Z. Dong, C. Chen, S. Wu, J. Sun, Chin. J. Org. Chem., 2017, $37,2544-2554$.

[171] M. N. Hopkinson, A. D. Gee, V. Gouverneur, Chem. Eur. J., 2011, $17,8248-8262$

[172] H. A. Wegner, M. Auzias, Angew. Chem. Int. Ed., 2011, 50, 8236-8247.

[173] J. Um, H. Yun, S. Shin, Org. Lett., 2016, 18, 484-487.

[174] B. Alcaide, P. Almendros, E. Busto, A. Luna, Adv. Synth. Catal., 2016, 358, 1526-1533.

[175] A. Tlahuext-Aca, M. N. Hopkinson, R. A. Garza-Sanchez, F. Glorius, Chem. Eur. J., 2016, 22, 5909-5913.

[176] B. Alcaide, P. Almendros, E. Busto, F. Herrera, C. Lázaro-Milla, A. Luna, Adv. Synth. Catal., 2017, 359, 2640-2652.

[177] B. Alcaide, P. Almendros, E. Busto, C. Lázaro-Milla, J. Org. Chem., 2017, 82, 2177-2186.

[178] Z. Xia, O. Khaled, V. Mouriès-Mansuy, C. Ollivier, L. Fensterbank, J. Org. Chem., 2016, 81, 7182-7190.

[179] C. Qu, S. Zhang, H. Du, C. Zhu, Chem. Commun., 2016, 52, 14400-14403.

[180] A. H. Bansode, S. R. Shaikh, R. G. Gonnade, N. T. Patil, Chem. 
Commun., 2017, 53, 9081-9084.

[181] Z. S. Wang, T. D. Tan, C. M. Wang, D. Q. Yuan, T. Zhang, P. Zhu, C. Zhu, J. M. Zhou, L. W. Ye, Chem. Commun., 2017, 53, 6848-6851.

[182] H. Li, Z. Cheng, C. H. Tung, Z. Xu, ACS Catal., 2018, 8, 8237-8243.

[183] A. Sagadevan, A. Ragupathi, K. C. Hwang, Angew. Chem. Int. Ed., 2015, 54, 13896-13901.

[184] A. Ragupathi, V. P. Charpe, A. Sagadevan, K. C. Hwang, Adv. Synth. Catal., 2017, 359, 1138-1143.

[185] L. Huang, M. Rudolph, F. Rominger, A. S. K. Hashmi, Angew. Chem. Int. Ed., 2016, 55, 4808-4813.

[186] J. R. Deng, W. C. Chan, N. C. H. Lai, B. Yang, C. S. Tsang, B. C. B. Ko,
S. L. F. Chan, M. K. Wong, Chem. Sci., 2017, 8, 7537-7544.

[187] Y. Liu, Y. Yang, R. Zhu, C. Liu, D. Zhang, Chem. Eur. J., 2018, 24, 14119-14126.

[188] J. Hou, A. Ee, W. Feng, J. H. Xu, Y. Zhao, J. Wu, J. Am. Chem. Soc., 2018, 140, 5257-5263.

[189] A. Mishra, P. Rai, M. Srivastava, B. P. Tripathi, S. Yadav, J. Singh, J. Singh, Catal. Lett., 2017 147, 2600-2611.

[190] G. S. Jang, J. Lee, J. Seo, S. K. Woo, Org. Lett., 2017, 19, 6448-6451. [191] K. Wang, L. G. Meng, L. Wang, Org. Lett., 2017, 19, 1958-1961.

[192] D. Wei, F. Liang, Org. Lett., 2016, 18, 5860-5863.

[193] K. Ni, L. G. Meng, K. Wang, L. Wang, Org. Lett., 2018, 20, 2245-2248.

\title{
可见光促进的炔烃的双官能团化反应
}

\author{
任 翔, 陆 展 ${ }^{*}$ \\ 浙江大学化学系, 浙江杭州 310058
}

\begin{abstract}
摘要: 炔烃是一类易于制备且来源广泛的化合物, 具有很高的反应活性. 炔烃的双官能团化反应是一种直接、高效地构建 各类有用分子骨架的策略. 可见光作为一种绿色、清洁、来源广泛且丰富的能源, 近几年在化学领域受到广泛关注, 在烯 烃的双官能团化等反应中有着重要应用. 可见光促进的炔烃双官能团化反应在过去几年也得到了迅猛的发展. 本综述从 可见光促进的自由基历程, 以及可见光促进与过渡金属联用两个方面讨论了可见光促进的炔烃双官能团化反应.

可见光催化剂具有独特的单电子氧化还原特性, 可与底物发生单电子转移, 生成相应的自由基. 一方面, 各类型自由 基如碳 $\left(s p^{3}, s p^{2}\right)$ 自由基和杂原子 $(\mathrm{P}, \mathrm{S}, \mathrm{N}, \mathrm{Se}, \mathrm{Br}, \mathrm{O})$ 自由基可在可见光促进下生成, 与碳碳参键发生自由基加成反应后, 生 成的烯基自由基在之后的转化中形成双官能团化产物. 自由基加成炔烃策略已被应用于一系列有用分子骨架的构建. 然 而, 该策略在内炔烃及脂肪族炔烃上表现不佳. 同时, 其区域选择性和立体选择性也尚待提高. 作为补充, 可见光促进的单 电子氧化还原形成1,3-偶极子与炔烃发生环加成反应的策略也在近期得到发展, 但该类反应因需要特定的反应前体而受到 限制. 另一方面, 可见光促进的单电子氧化炔烃, 进而与亲核试剂反应的方法同样在近期得到发展. 该方法为炔烃的双官 能团化反应提供了新的思路. 然而, 炔烃较高的还原电势是该方法尚待解决的一个难题.

利用过渡金属配合物可与参键配位发生环金属化或者插入反应的特性, 采用可见光促进与过渡金属联用策略来实现 炔烃的双官能团化反应也受到研究者的重视. 金属配合物在可见光照射下被活化, 活化后的金属物种可与炔烃反应生成 烯基金属物种, 该物种为炔烃双官能团化的活性中间体. 该策略可以高效地转化内炔烃和末端炔烃, 同时其产物具有较高 的区域选择性. 然而, 该策略对脂肪族炔烃的转化效率尚待提高, 其产物的立体选择性问题仍需要解决. 同时, 发展地球丰 产金属如铁、钴、镍等与可见光共同促进的炔烃双官能团化反应是该策略的发展方向之一.

综上, 我们总结并介绍了可见光促进的炔烃双官能团化反应. 我们相信该类反应的独特的反应历程, 温和的反应条件 以及反应特性将会吸引更多的科学家投入研究.
\end{abstract}

关键词: 可见光催化; 双官能团化; 环化; 炔烃; 氧化还原催化剂

收稿日期: 2018-11-18. 接受日期: 2018-12-08. 出版日期: 2019-07-05.

*通讯联系人. 电话: (0571)88206919; 电子信箱: luzhan@zju.edu.cn

基金来源：浙江省自然科学基金(LR19B020001); 国家自然科学基金(21472162，21772171); 国家重点基础研究发展计划 (2015CB856600).

本文的电子版全文由Elsevier出版社在ScienceDirect上出版(http://www.sciencedirect.com/science/journal/18722067). 